\title{
The CU 2-D-MAX-DOAS instrument - Part 2: Raman scattering probability measurements and retrieval of aerosol optical properties
}

\author{
Ivan Ortega ${ }^{1,2}$, Sean Coburn ${ }^{1,2}$, Larry K. Berg ${ }^{3}$, Kathy Lantz ${ }^{2,4}$, Joseph Michalsky ${ }^{2,4}$, Richard A. Ferrare ${ }^{5}$, \\ Johnathan W. Hair ${ }^{5}$, Chris A. Hostetler ${ }^{5}$, and Rainer Volkamer ${ }^{1,2}$ \\ ${ }^{1}$ Department of Chemistry and Biochemistry, University of Colorado, Boulder, CO, USA \\ ${ }^{2}$ Cooperative Institute for Research in Environmental Sciences (CIRES), Boulder, CO, USA \\ ${ }^{3}$ Pacific Northwest National Laboratory, Richland, WA, USA \\ ${ }^{4}$ Global Monitoring Division, Earth System Research Laboratory, NOAA, Boulder, CO, USA \\ ${ }^{5}$ NASA Langley Research Center, Hampton, VA, USA \\ Correspondence to: Rainer Volkamer (rainer.volkamer@colorado.edu)
}

Received: 8 December 2015 - Published in Atmos. Meas. Tech. Discuss.: 18 January 2016

Revised: 12 July 2016 - Accepted: 13 July 2016 - Published: 23 August 2016

\begin{abstract}
The multiannual global mean of aerosol optical depth at $550 \mathrm{~nm}\left(\mathrm{AOD}_{550}\right)$ over land is $\sim 0.19$, and that over oceans is $\sim 0.13$. About $45 \%$ of the Earth surface shows $\mathrm{AOD}_{550}$ smaller than 0.1 . There is a need for measurement techniques that are optimized to measure aerosol optical properties under low AOD conditions. We present an inherently calibrated retrieval (i.e., no need for radiance calibration) to simultaneously measure AOD and the aerosol phase function parameter, $g$, based on measurements of azimuth distributions of the Raman scattering probability (RSP), the near-absolute rotational Raman scattering (RRS) intensity. We employ radiative transfer model simulations to show that for solar azimuth RSP measurements at solar elevation and solar zenith angle (SZA) smaller than $80^{\circ}$, RSP is insensitive to the vertical distribution of aerosols and maximally sensitive to changes in AOD and $g$ under nearmolecular scattering conditions. The University of Colorado two-dimensional Multi-AXis Differential Optical Absorption Spectroscopy (CU 2-D-MAX-DOAS) instrument was deployed as part of the Two Column Aerosol Project (TCAP) at Cape Cod, MA, during the summer of 2012 to measure direct sun spectra and RSP from scattered light spectra at solar relative azimuth angles (SRAAs) between 5 and $170^{\circ}$. During two case study days with (1) high aerosol load (17 July, $\left.0.3<\mathrm{AOD}_{430}<0.6\right)$ and $(2)$ near-molecular scattering conditions (22 July, AOD $_{430}<0.13$ ) we compare RSP-based
\end{abstract}

retrievals of $\mathrm{AOD}_{430}$ and $g$ with data from a co-located CIMEL sun photometer, Multi-Filter Rotating Shadowband Radiometer (MFRSR), and an airborne High Spectral Resolution Lidar (HSRL-2). The average difference (relative to DOAS) for $\mathrm{AOD}_{430}$ is $+0.012 \pm 0.023$ (CIMEL), $-0.012 \pm 0.024 \quad$ (MFRSR), $\quad-0.011 \pm 0.014 \quad$ (HSRL$2)$ and $+0.023 \pm 0.013 \quad\left(\right.$ CIMEL $_{\mathrm{AOD}}-$ MFRSR $\left._{\mathrm{AOD}}\right)$ and yields the following expressions for correlations between different instruments: DOAS $_{\mathrm{AOD}}=$ $-(0.019 \pm 0.006)+(1.03 \pm 0.02) \times$ CIMEL $_{\mathrm{AOD}}$ $\left(R^{2}=0.98\right), \quad$ DOAS $_{\mathrm{AOD}}=-(0.006 \pm 0.005)+(1.08 \pm$ $0.02) \times$ MFRSR $_{\mathrm{AOD}} \quad\left(R^{2}=0.98\right)$, and CIMEL $_{\mathrm{AOD}}=$ $(0.013 \pm 0.004)+(1.05 \pm 0.01) \times \operatorname{MFRSR}_{\mathrm{AOD}}\left(R^{2}=0.99\right)$ The average $g$ measured by DOAS on both days was $0.66 \pm 0.03$, with a difference of $0.014 \pm 0.05$ compared to CIMEL. Active steps to minimize the error in the RSP help to reduce the uncertainty in retrievals of AOD and $g$. As AOD decreases and SZA increases, the RSP signal-to-noise ratio increases. At $\mathrm{AOD}_{430} \sim 0.4$ and 0.10 the absolute AOD errors are $\sim 0.014$ and 0.003 at $70^{\circ}$ SZA and 0.02 and 0.004 at $35^{\circ} \mathrm{SZA}$. Inherently calibrated, precise AOD and $g$ measurements are useful to better characterize the aerosol direct effect in urban polluted and remote pristine environments. 


\section{Introduction}

Atmospheric aerosol particles play a key role in the energy balance of Earth's atmosphere (IPCC, 2013). The aerosol optical depth (AOD), defined as a vertical integral of the aerosol extinction coefficient from the Earth surface to the top of the atmosphere, is an important input to assessments of how the atmospheric aerosol burden affects the budget of incoming solar radiation in global climate models (Hansen et al., 2002; Chung et al., 2005; McComiskey et al., 2008). McComiskey et al. (2008) studied the sensitivity of aerosol direct radiative forcing using representative uncertainties in currently established methods to measure aerosol optical properties. For a typical AOD uncertainty of 0.01 (best case scenario expected for newly calibrated ground-based radiometric instrument in the visible spectra range; Eck et al., 1999; Holben et al., 1998), the error in the aerosol direct forcing is about $0.6 \mathrm{~W} \mathrm{~m}^{-2}$ (top of the atmosphere) and $1.3 \mathrm{~W} \mathrm{~m}^{-2}$ (surface) for a solar zenith angle (SZA) of $45^{\circ}$ (McComiskey et al., 2008). The multiannual global mean $\mathrm{AOD}_{550}$ estimated from satellites finds that about 28 and $43 \%$ of the land surface and 15 and $46 \%$ of the ocean surface have AOD $\leq 0.05$ and $\leq 0.1$ (Remer et al., 2008); current ground-based networks capture frequent AOD values below 0.15 (Holben et al., 2001; Augustine et al., 2008; Michalsky et al., 2010; Mao et al., 2014). Low AOD conditions are projected to be more prevalent in the future (Westervelt et al., 2015). Under these conditions, measurements of AOD with higher accuracy and precision are even more desirable.

Traditional AOD measurements often employ radiometric calibrated instruments, e.g., CIMEL sun photometer (Holben et al., 1998) and Multifilter Rotating Shadowband Radiometer (MFRSR) (Harrison et al., 1994). In general, the retrieval of AOD is estimated based on the extinction of the direct sun irradiance measurements. The quality of such measurements is improved under high AOD and cloud-free conditions. In contrast, under molecular scattering conditions, i.e., $\mathrm{AOD}_{430}<0.13$ (Rayleigh scattering extinction under overhead sun conditions), the measurements become subject to higher relative uncertainties (Holben et al., 1998). Holben et al. (1998) pointed out that the error in AOD by means of solar sky brightness (scattering) in the solar aureole region may be lower than traditional direct sun extinction methods. However, to our knowledge, this has not previously been exploited in measurements to date.

Multi-axis differential optical absorption spectroscopy (MAX-DOAS) can simultaneously retrieve trace gases and aerosol optical properties (Hönninger et al., 2004; Wagner et al., 2004; Frieß et al., 2006; Clémer et al., 2010). The MAXDOAS technique relies on spectrally resolved solar scattered light measurements at several elevation angles (EAs), defined between the horizon and zenith (Hönninger et al., 2004). The retrieval approach does not require radiometric calibration, and the trace gases and aerosol optical properties are measured relative to a reference spectrum, typically recorded in the zenith. Measurements at low EA have maximum sensitivity in the lowermost part of the atmosphere. More recently, two-dimensional MAX-DOAS (2-D-MAX-DOAS) has been shown to be a promising technique to measure the trace gas variability around the measurement site from scattered light spectra at different azimuth angles (AAs), defined relative to north (Wang et al., 2014; Ortega et al., 2015). The University of Colorado (CU) 2-D-MAX-DOAS instrument has demonstrated range-resolved measurements of $\mathrm{NO}_{2}$ and oxygenated hydrocarbons from azimuth scans at low EA. The spatial scale probed by 2-D-MAX-DOAS closely resembles the grid-cell size of atmospheric models and satellite pixels and can be used to systematically characterize chemical gradients under inhomogeneous conditions (Ortega et al., 2015).

In this paper we exploit solar azimuth scattered light and direct sun measurements to assess aerosol column properties using solar almucantar measurements. The information content regarding aerosol properties using this geometry has been discussed in detail for radiance measurements with single wavelength channel detectors elsewhere (Box and Deepak, 1979; Nakajima et al., 1983; Kaufman et al., 1994; Bohren and Huffman, 1998; Dubovik et al., 2000). We use solar almucantar scans in combination with hyperspectral measurements and describe a new retrieval scheme to estimate $\mathrm{AOD}_{430}$ and aerosol phase functions (simplified by $g$, Henyey-Greenstein (HG) approximation) based on quantitative analysis of the rotational Raman scattering (RRS) by atmospheric molecules (Ring effect) (Grainger and Ring, 1962; Chance and Spurr, 1997). RRS causes "filling-in" of the solar Fraunhofer lines and has to be taken into account to accurately estimate absorption of trace gases using passive DOAS techniques (Platt and Stutz, 2008). Several studies have described the quantitative analysis of RRS and its effect in solar scattering UV-vis observations (Vountas et al., 1998, 2003; de Beek et al., 2001; Langford et al., 2007). The quantitative analysis of RRS by DOAS was introduced by Wagner et al. (2004, 2009a) with the so-called Raman scattering probability (RSP) (the probability that a detected photon has undergone a rotational Raman scattering event). Under cloud-free conditions the AOD has a strong effect on the RSP, which further exhibits a high dependency on the solar relative azimuth angle (Wagner et al., 2009b, 2014). To the best of our knowledge, there has been no previous measurement of AOD and $g$ using almucantar scans of RSP by MAX-DOAS.

\section{Experimental}

\subsection{The Two-Column Aerosol Project (TCAP) field campaign}

The first phase of the Department of Energy (DOE) TCAP field campaign took place at Cape Cod, MA, during the summer of 2012 (Berg et al., 2016). TCAP was designed to pro- 
Table 1. Suite of measurements and products used in this work.

\begin{tabular}{|c|c|c|c|c|}
\hline Instrument & $\begin{array}{l}\text { Principle of } \\
\text { measurement }\end{array}$ & $\begin{array}{l}\text { Absolute radiometric } \\
\text { calibration (yes/no) }\end{array}$ & Products & Reference \\
\hline \multicolumn{5}{|c|}{ Ground-based instruments } \\
\hline 2-D-MAX-DOAS & Solar scattered light & no & AOD and $g(430 \mathrm{~nm})$ & Ortega et al. (2015) \\
\hline MFRSR & $\begin{array}{l}\text { Total and diffuse solar } \\
\text { irradiances }\end{array}$ & yes & $\begin{array}{l}\text { AOD }(430 \mathrm{~nm}) \text { calculated } \\
\text { using the Ångström exponent } \\
\text { between the standard wave- } \\
\text { lengths of } 415 \text { and } 500 \mathrm{~nm}\end{array}$ & Harrison et al. (1994) \\
\hline $\begin{array}{l}\text { CIMEL sun } \\
\text { photometer }\end{array}$ & $\begin{array}{l}\text { Direct solar beam and diffused } \\
\text { sky radiation }\end{array}$ & yes & $\begin{array}{l}\text { Level 2.0: } \\
\text { AOD }(430 \mathrm{~nm}) \text { calculated } \\
\text { using the Angström exponent } \\
\text { between the standard wavelengths } \\
\text { of } 340 \text { and } 440 \mathrm{~nm} \text { and } g(440 \mathrm{~nm})\end{array}$ & Holben et al. (1998) \\
\hline Radiosondes & $\begin{array}{l}\text { Weather balloon that measures } \\
\text { various atmospheric parameters }\end{array}$ & $\mathrm{n} / \mathrm{a}$ & $\begin{array}{l}\text { Vertical profiles of temperature, } \\
\text { pressure, and humidity } \\
\text { (four times per day) }\end{array}$ & Berg et al. (2015) \\
\hline \multicolumn{5}{|c|}{ Airborne instruments } \\
\hline HSRL-2 & $\begin{array}{l}\text { Backscatter and extinction } \\
\text { coefficients }\end{array}$ & & $\begin{array}{l}\text { AOD }(430 \mathrm{~nm}) \text { calculated using } \\
\text { the Ångström exponent between } \\
\text { the standard wavelengths } \\
\text { of } 355 \text { and } 532 \mathrm{~nm}\end{array}$ & Muller et al. (2014) \\
\hline
\end{tabular}

vide a comprehensive characterization of the aerosol direct and indirect effects under urban emission influences near the eastern coast of North America (over Cape Cod, MA) and to contrast it with observations in pristine conditions over the Atlantic Ocean. An extensive set of aerosol measurements was conducted aboard two research aircrafts (DOE G-1 and NASA B200) and with the DOE Atmospheric Radiation Measurement (ARM) ground mobile facility (located over Cape Cod, MA, USA); for details see Berg et al. (2016). The CU 2-D-MAX-DOAS was deployed at the ARM ground site from 1 July to 13 August 2012 to test its innovative capabilities to measure aerosol optical properties and trace gases simultaneously with a single instrument. Here, we focus primarily on 22 July 2012 due to its low AOD and cloud-free conditions and the available complementary data (Berg et al., 2016; Ortega et al., 2016). The retrieval approach is also applied for a high AOD case study on 17 July 2012. The TCAP data set provides an excellent opportunity to evaluate the robustness of the RSP-based retrieval approach and to compare the products with independent instruments. Table 1 and Sect. 2.6 present other measurements and products used in this work.

\subsection{2-D-MAX-DOAS measurements}

The 2-D-MAX-DOAS telescope and detection system has been described in detail elsewhere (Ortega et al., 2015). The angles defining the geometry of measurements are illustrated in Fig. 1. The CU 2-D-MAX-DOAS instrument conducts

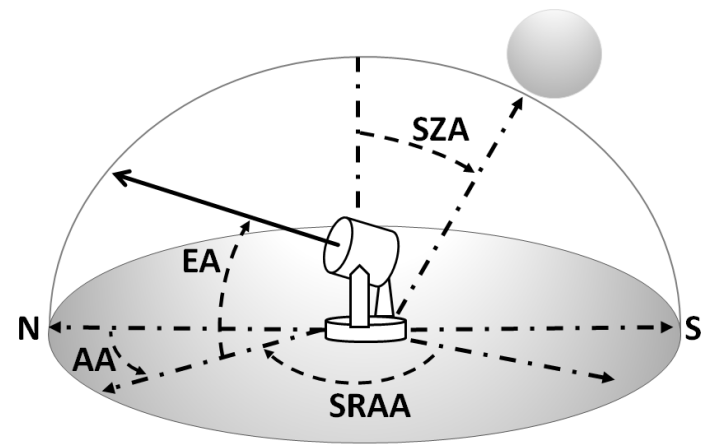

Figure 1. Sketch of measurement geometry used with the 2-DMAX-DOAS. The solid line coming out from the telescope represents the azimuth angle (AA) with respect to north, characterized by the elevation angle (EA) and solar relative azimuth angle (SRAA). SZA is the solar zenith angle.

measurements in three different modes: (1) off-axis scan, in which several EAs and zenith are used with a fixed AA relative to north; (2) almucantar scan, in which solar scattered photons are collected using any EA for multiple solar relative azimuth angles (SRAAs). To further enhance the aerosol information content and estimate uniformity (homogeneity) around the measurement site the almucantar scan is carried out on the left and right side of the solar disc. Up to now, this particular geometry has not been used with MAX-DOAS; however it is widely used by the CIMEL sun photometer 
Table 2. Geometry of measurements and configuration used during the TCAP field campaign.

\begin{tabular}{lllll}
\hline Mode & EA $\left(^{\circ}\right)$ & AA $\left(^{\circ}\right)$ & SRAA $\left(^{\circ}\right)$ & Total acquisition time (min) \\
\hline 1 & $1,3,6,8,10,30,45,90$ & 0,180 & variable & $16-17^{\mathrm{a}}$ \\
2 & Solar elevation $(90-$ SZA) and 45 & variable & $5,10,15, \ldots, 180$ (left and right) & $2-3^{\mathrm{b}}$ \\
3 & Solar elevation & variable & 0 & $2-6$ \\
\hline
\end{tabular}

${ }^{\mathrm{a}}$ Integration time of $60 \mathrm{~s}$ at each EA. ${ }^{\mathrm{b}}$ Integration time of $1 \mathrm{~s}$ at each SRAA.

using single wavelength channel detectors at solar elevation $\left(\mathrm{EA}=90^{\circ}-\mathrm{SZA}\right)$ (Holben et al., 1998). Lastly, (3) direct sun observations inherently minimize RSP.

The 2-D-MAX-DOAS instrument deployed during TCAP at the ARM Mobile Facility consisted of three synchronized spectrograph/detector units located indoors in a temperaturecontrolled sea container, the control measurement laptop, and the 2-D telescope located outdoors. The telescope was deployed on top of one seatainer ( $\sim 45 \mathrm{~m}$ a.s.l.), providing an unobstructed view close to the horizon in a $\sim 360^{\circ}$ azimuth view. The only small obstruction in the azimuth scan was an independent sampling inlet pillar located in the middle of the seatainer. The light collected with the telescope was focused onto a single CeramOptics $25 \mathrm{~m} \times 1.0 \mathrm{~mm}$ silica mono fiber coupled to a trifurcated fiber bundle connected to three Ocean Optics (QE65000) spectrometers collecting solar light between 300 and $631 \mathrm{~nm}$ with a spectral resolution between 0.4 and $0.6 \mathrm{~nm}$ (FWHM). The same spectrometer system was used in the remote tropical Pacific Ocean for the detection of glyoxal (Sinreich et al., 2010). The electronic rack containing the spectrograph/detectors was temperature controlled $\left(34^{\circ} \mathrm{C}, 0.005^{\circ} \mathrm{C}\right.$ peak to peak variation) and CCDs cooled to $-30^{\circ} \mathrm{C}$ to minimize dark current.

\subsubsection{Configuration of the azimuth scan}

The instrument was configured to conduct measurements of direct sunlight, and scattered sunlight using a sequence of EA and AA pairs described in Table 2. The off-axis scan consisted of seven EAs and zenith, and spectra were recorded using an integration time of $1 \mathrm{~min}$ at each angle, alternating south and north AAs (total acquisition time of 16-17 min). This specific geometry was used in order to know the effect of elevated aerosol layers in the apparent absorption of the oxygen collision complex $\left(\mathrm{O}_{2}-\mathrm{O}_{2}\right)$ as seen by the 2-DMAX-DOAS (Ortega et al., 2016). At the end of the EA scan, the almucantar scan was implemented with an integration time of $1 \mathrm{~s}$ with 70 angles relative to the sun in steps of $5^{\circ}$ up to $180^{\circ}$ on the left and right sides of the solar disk at solar EA. The almucantar scan was repeated for a fixed EA of $45^{\circ}$. The total acquisition time of the azimuth scan was 2-3 min. In this work, we focus only on the almucantar scan at solar EA. The advantages of evaluating azimuth scan at solar EA consist in the enhanced sensitivity towards aerosol phase functions and minimizing the effect of aerosol inhomogeneity at small SZA. The full measurement cycle between EA and almucantar scans took about $20 \mathrm{~min}$ and was repeated sequentially. The initial solar almucantar alignment procedure to achieve pointing accuracy better than the motors internal encoder resolution $\left(0.17^{\circ}\right)$ is described in detail by Ortega et al. (2015). Briefly, the initial alignment is carried out in the field by measuring rapid ( $1 \mathrm{~s}$ integration time) solar scattered spectra with several small SRAAs (usually $-5^{\circ}<$ SRAA $<5^{\circ}$; negative SRAAs are to the left and positive values are to the right side of the sun). The alignment is achieved when measurements of intensities (in counts s ${ }^{-1}$ ) on the right and left sides present symmetry and the offset estimated with a Gaussian fit of the intensities at the center of the sun's disk is small $\left(<0.17^{\circ}\right)$ and accounted for in the software. To avoid saturation of the detector, this alignment procedure was performed below and above the sun position (see Fig. 2 in Ortega et al., 2015). The telescope field of view (FOV) of this viewing port was determined by introducing light into the fiber retrospectively from the exit side, and the divergence of the light after exiting the telescope was evaluated to have a full opening angle of $0.6^{\circ}$ in agreement with the theoretical FOV based on the experimental field setup.

\subsubsection{Direct sun mode}

During the first phase of TCAP, for cloud-free days, direct sun spectra were recorded periodically with a total integration time of $2-4 \mathrm{~min}$. In order to reduce the intensity of the direct sun beam and avoid saturation of the detector the light is collected via an integrating sphere with a diameter of $2.54 \mathrm{~cm}$. The sphere also serves for correcting pointing inaccuracies and atmospheric lens effects (Herman et al., 2009). To minimize the contribution of solar scattered photons in the direct sun mode a black anodized collimator tube with a full opening angle of $2.9^{\circ}$ was used. A sketch of the housed optics integrating the direct sun and azimuth ports is shown in Fig. 1 in Ortega et al. (2015). The custom software developed in LabView uses the exact coordinate location and heading (defined as zero corresponding to true north) to operate the 2-D telescope. This information is used as Euler angles to correct the astronomical solar position and locate the sun in the sky. This step is similar to the crude alignment of advanced solar trackers, which apply active imaging of the solar disk for precise pointing (Gisi et al., 2011; Baidar et al., 2016). We do not aim to track the sun in this work. The purpose of the 


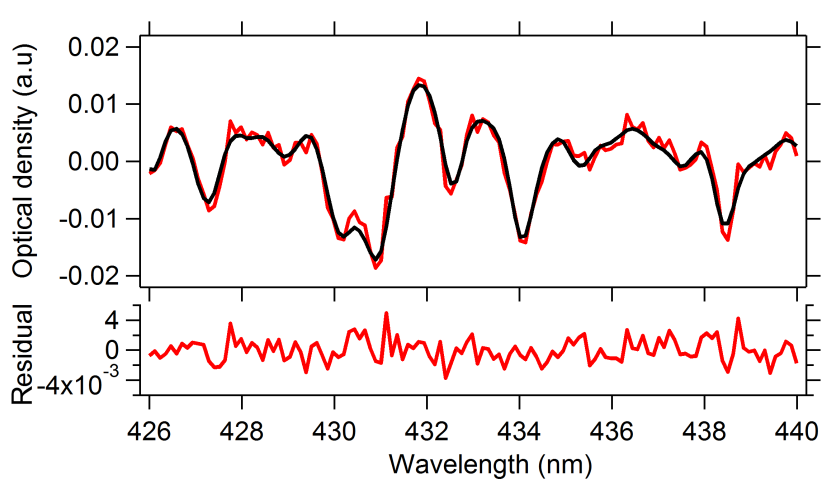

Figure 2. Top: example of spectral proof for the detection of dRSP (1 s integration time) using the solar azimuth scan on 22 July 2012 at $7: 43 \mathrm{LST}\left(\mathrm{SZA}=66.3^{\circ}, \mathrm{SRAA}=120^{\circ}, \mathrm{EA}=\right.$ solar EA $)$. The red line represents the measured spectra and black line is the fitted normalized Ring cross section. The dRSP is $0.0502 \pm 0.0011$. Bottom: residual from the DOAS fit, $\mathrm{RMS}_{\text {meas }}=1.58 \times 10^{-3}$, is in good agreement with the shot-noise $\mathrm{RMS}_{\text {theo }}=1.40 \times 10^{-3}$ based on photon counting statistics.

direct sun mode is to obtain spectra that are nearly free of RRS and use these direct sun spectra as reference spectra in the retrieval of RSP. To assess pointing accuracy of the direct sun observation we use the solar azimuth scan alignment as explained in Sect. 2.2.1.

\subsection{DOAS retrieval of differential RSP and intensities}

The main products retrieved with the solar azimuth scan are the non-calibrated spectral intensities $\left(I_{\text {norm }}\right)$ and the strength of RRS by atmospheric molecules (RSP). The spectra intensities were corrected by electronic offset and dark current, and the number of CCD-pixel counts were normalized by the integration time (units of counts $\mathrm{s}^{-1}$ ) at a certain wavelength $(\lambda)$. These normalized $I_{\text {norm }}$ are used for quality assurance of homogeneity and to calculate pointing accuracy only. The differential RSP (dRSP; differential with regards to the amount contained in the reference spectrum) was retrieved by its specific narrow band signatures $(<1 \mathrm{~nm})$ at $\mathrm{UV}$-vis wavelengths (Fig. 2), which are separated well from broadband molecule and aerosol extinction using the DOAS method (Platt and Stutz, 2008). We follow the retrieval strategy introduced in Wagner et al. (2009a) and apply the DOAS settings from Wagner et al. (2009b) to retrieve the RSP in the fitting window of $426-440 \mathrm{~nm}$. The only atmospheric cross section absorber adjusted to the spectrometer resolution that is included in the analysis is $\mathrm{NO}_{2}$ (Vandaele et al., 1998). A thirdorder polynomial is fitted to account for broad band spectral structures. A direct sun spectrum recorded at low SZA $\left(28^{\circ}\right)$ on 22 July 2012 is used as reference spectrum to evaluate the dRSP in the azimuth scan mode. The Ring cross section is calculated from the respective sun-observation spectrum using the DOASIS software (Kraus, 2006), which then is nor-

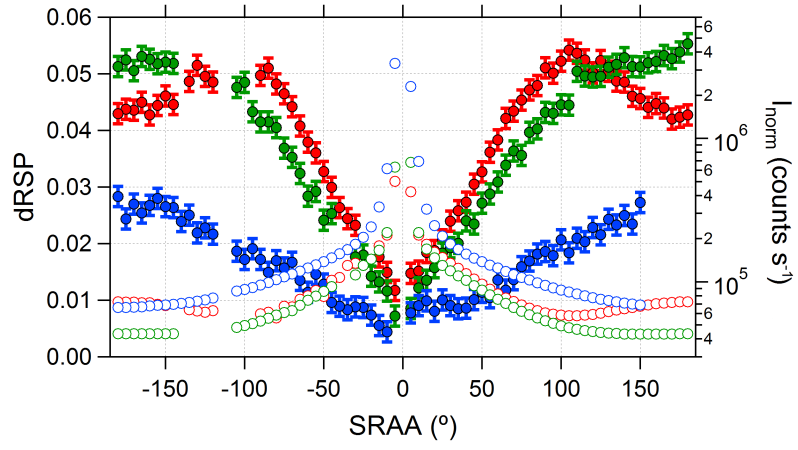

Figure 3. Example of the SRAA dependence of dRSP (filled circles) and $I_{\text {norm }}$ (open circles) measured at the solar elevation near $430 \mathrm{~nm}$ for three SZAs: (red) $66.5^{\circ}$ (7:42 LST), (green) $49.0^{\circ}$ (9:17 LST), and (blue) $22.0^{\circ}$ (12:40 LST).

malized by removing the continuum component with a thirdorder polynomial high pass filter (Wagner et al., 2009a). The spectra were analyzed using the WinDOAS software package (Fayt and Van Roozendael, 2001).

Examples of the DOAS fit analysis are shown in Figs. 2 and S1. Systematic errors in the retrieval of dRSP were quantified by means of sensitivity studies. The sensitivity of the DOAS settings were explored by changing the wavelength intervals and polynomial orders in a similar way as performed by Vogel et al. (2013). These sensitivity tests reveal a remarkable stability towards changing the DOAS fitting window using different polynomial orders, for small and high SRAAs, and different SZAs (see Figs. S2-S4; difference $<5 \%$; the same analysis in the UV, Fig. S5, yields two times greater DOAS fit error and root mean square (RMS) due to the smaller signal-to-noise ratio achieved with $1 \mathrm{~s}$ integration time). The typical value of the dRSP fit error is $\sim 0.0018$, calculated internally in WinDOAS as the standard deviations on the retrieved dRSP; it interestingly does not depend strongly on the SRAA (see Figs. S1 and S6). We adopted this uncertainty in the final error propagation of the aerosol optical properties (see Sect. 3.3.1). Sensitivity towards fitting an intensity offset (to correct for stray light) has been carried out. However, the magnitude of the RSP becomes noisier and extremely high (about 2 times greater), which is not supported by our radiative transfer simulations (see Sect. 2.4).

Figure 3 shows typical examples of the measurements of dRSP and $I_{\text {norm }}$ obtained with the solar azimuth scan (mode 2) for three different SZAs. The SRAA scan is from $-180^{\circ}$ (left side of the sun) to $+180^{\circ}$ (right side of the sun). The dRSP decreases for small SRAAs due to fewer scattering events by molecules and a dominant aerosol forward scattering. In contrast, the $I_{\text {norm }}$ increases for small SRAAs due to the strong probability of aerosol scattering in the forward direction. The second important aspect is the SZA dependency. Previous studies have established the relationship be- 
tween the SRAA, SZA, and the effective aerosol scattering angles (Nakajima et al., 1996; Torres et al., 2013). In general, the information content of the azimuth scan is maximized by using high SZAs. The maximum dRSP values (corresponding to a minimum $I_{\text {norm}}$ ) are shown at SRAA of $100^{\circ}$ (for $\mathrm{SZA}=66^{\circ}$ ), which indicates to some degree the high sensitivity to aerosol scattering processes (aerosol phase function). The dRSP decreases for low SZA (blue circles).

\subsection{Radiative transfer simulations}

We use the full spherical Monte Carlo atmospheric radiative transfer model (McArtim) (Deutschmann et al., 2011) to simulate and interpret the measurements. McArtim has been successfully tested and compared with other radiative transfer models (Wagner et al., 2007). McArtim simulates atmospheric photon transfer using the optical properties described by several input parameters such as vertical profiles of pressure, temperature, and aerosol extinction characterized with aerosol phase functions, typically represented by $g$, and single scattering albedo (SSA). McArtim calculates the absolute RSP using the fraction of scattering events that have presented RRS (inelastic scattering). Reflection at the surface is characterized with the surface albedo (SA) and is treated as Lambertian. The modeled RSP from McArtim has been previously characterized and used in several studies (Wagner et al., 2009b, 2010, 2014). Several general input parameters are required and kept constant in the forward modeling. An altitude grid of $100 \mathrm{~m}$ up to $10 \mathrm{~km}, 200 \mathrm{~m}$ up to $50 \mathrm{~km}$, and 5 up to $100 \mathrm{~km}$ was used. The FOV was set to $0.6^{\circ}$ (similar to the full opening angle of the telescope; see Sect. 2.2.1). The wavelength chosen to forward model the RSP is $430 \mathrm{~nm}$, representing the middle wavelength of the fitting window and characteristic $\mathrm{Ca}$ lines of the Fraunhofer spectrum (Wagner et al., 2010). In this section we describe the different sensitivity studies that were performed in order to understand the effect of aerosol optical properties in the measured RSP using the solar azimuth scan geometry. For the sensitivity studies we use the pressure, temperature, and $\mathrm{RH}$ profiles taken from the US Standard Atmosphere. We have adopted the geometry of typical 2-D-MAX-DOAS measurement taken from TCAP, i.e., similar SRAAs $\left(-180\right.$ to $\left.+180^{\circ}\right)$ and SZA ranges.

\subsubsection{Sensitivity of RSP to aerosol distribution}

Figure $4 \mathrm{a}$ presents the effect of AOD on the simulation of RSP in the azimuth scan for a single SZA $\left(70^{\circ}\right)$. Additional input properties are SSA $=0.98, g=0.70, \mathrm{SA}=0.05$, and homogeneous extinction height of $1.5 \mathrm{~km}$. As expected (see Fig. 3), the RSP decreases and the radiance increases for angles close to the sun (see Fig. 4a). In general, the RSP decreases with increasing AOD due to the decrease of molecular scattering and higher probability of aerosol elastic scattering (see Sect. 3.3 for further analysis regarding maximal low AOD information). Figure 4a also shows that the maxi-

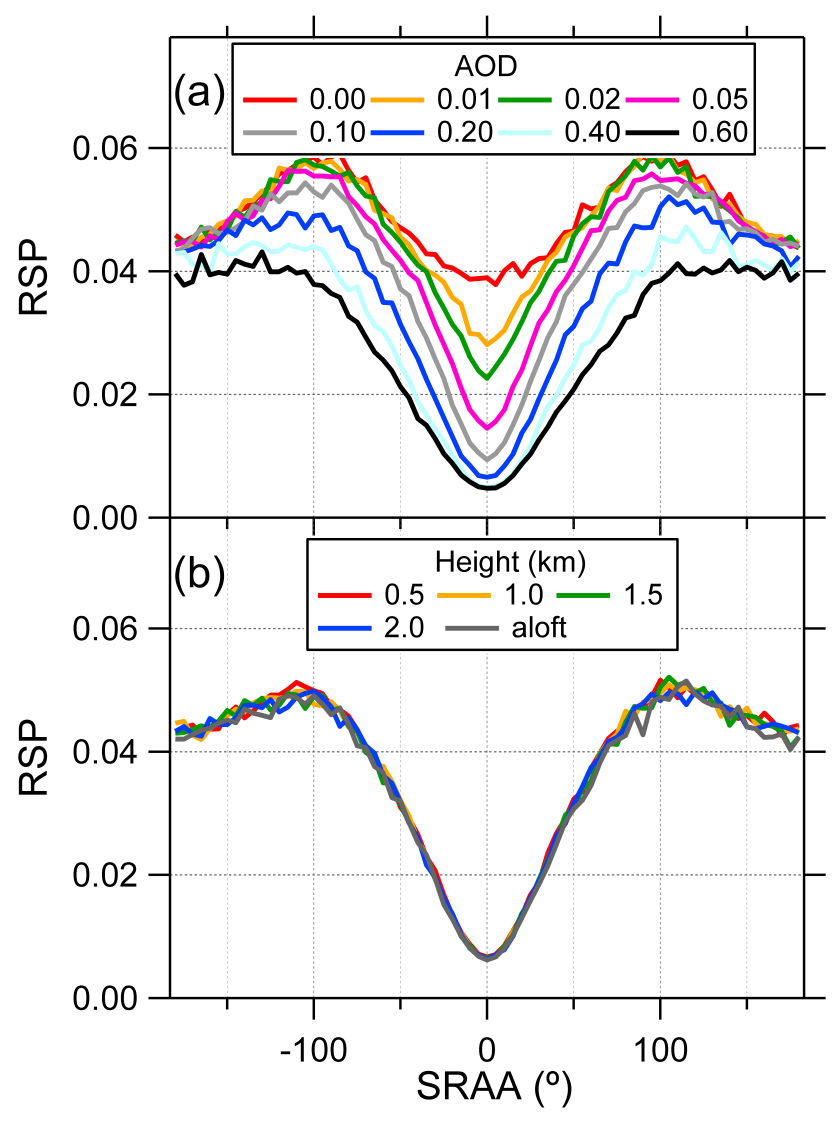

Figure 4. Sensitivity study showing that simulated RSP $(430 \mathrm{~nm})$ is (a) a strong function of AOD and (b) insensitive to the aerosol vertical distribution. (a) AOD is varied, keeping aerosols homogeneously distributed (box profile) up to $1.5 \mathrm{~km}$ altitude. (b) The aerosol extinction vertical distribution is varied for a constant AOD of 0.2 . The simulation is for $\mathrm{SZA}=70^{\circ}, \mathrm{SSA}=0.98, g=0.70$, $\mathrm{SA}=0.05$.

mum RSP is at about $90-100^{\circ}$, in agreement with our measurements at similar SZA (see Fig. 3a). Figure 4b shows the sensitivity of the RSP with respect to the aerosol extinction vertical distribution, while keeping the AOD constant at 0.2 (additional parameters are the same as before). Several homogeneous extinction vertical profiles from altitudes of 0.5 $2.0 \mathrm{~km}$ are studied as well as a case of aerosol extinction aloft, assuming maximum extinction at $2.8 \mathrm{~km}$ with a width of $2.8 \mathrm{~km}$. Similar results are obtained also at small and high SZAs (see Fig. S7). It is clear that the aerosol extinction vertical distribution does not play a significant role in the simulation of RSP in the azimuth scan. Systematic elevated aerosol extinction layers were identified during TCAP (Berg et al., 2016; Ortega et al., 2016), and have been compared with model predicted aerosol profiles (Fast et al., 2016). Previous studies have shown that RSP is primarily sensitive to the AOD (Wagner et al., 2009b) and recognize the value of measurements at small SRAAs to obtain information about $g$ (Holben et al., 1998; Wagner et al., 2009b). The sensi- 


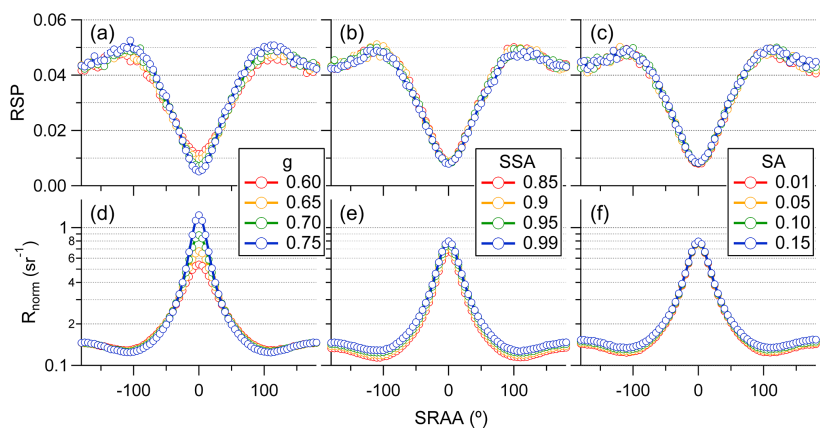

Figure 5. Sensitivity study showing simulated RSP (top row) and sun-normalized radiances, $R_{\text {norm }}\left(\mathrm{sr}^{-1}\right)$, defined as the ratio of the radiance $\left(\mathrm{W} \mathrm{m}^{2} \mathrm{sr}^{-1}\right)$ in the geometry indicated to the solar irradiance $\left(\mathrm{W} \mathrm{m}^{2}\right.$ ) (bottom row) at $430 \mathrm{~nm}$ for several input parameters: (a, b) $g$, (c, d) SSA, and (e, f) SA. The simulations were carried out assuming a box extinction profile (1.5 km height) with an AOD of 0.2 and $\mathrm{SZA}=70^{\circ}$.

tivity studies in Figs. 3, 4, and the Supplement (Fig. S7) confirm that the RSP does not depend on the aerosol vertical distribution for SZA smaller than $80^{\circ}$. Note that all of the azimuth scans here were conducted at solar EA, which for measurements at $\mathrm{SZA}<80^{\circ}$ corresponds to EAs of $10^{\circ}$ or higher. For measurements at low EAs the RSP becomes slightly dependent on the aerosol vertical distribution (see Fig. S8c). Hence, the RSP is suitable to characterize column properties of AOD and the aerosol phase function, $g$. The elevated aerosol layers documented by Berg et al. (2016) during TCAP hence are captured and do not present a limitation for this work. Section 3.2 describes in more detail the aerosol inhomogeneity on both days.

\subsubsection{Sensitivity to $g$, SSA, and SA}

The second sensitivity study aimed to understand the effect of $g$, SSA, and SA. Figure 5 shows the results of the RSP and sun-normalized radiances, $R_{\text {norm }}\left(\mathrm{sr}^{-1}\right)$, defined internally in McArtim as the ratio of the radiance $\left(\mathrm{W} \mathrm{m}^{2} \mathrm{sr}^{-1}\right)$ of the geometry indicated to the solar irradiance $\left(\mathrm{W} \mathrm{m}^{2}\right)$, using a homogeneous aerosol extinction profile with an AOD of 0.2 (box height of $1.5 \mathrm{~km}$ ) and SZA of $70^{\circ}$. The asymmetry parameter, $g$, has the strongest effect on the RSP, especially for SRAA $<40^{\circ}$. The importance to the RSP of the geometry of measurements and its qualitative sensitivity towards aerosol phase functions was identified by Wagner et al. (2009b) using three different fixed azimuth directions. The RSP does not show a significant variability among different SSA, i.e., aerosol composition, but the sun-normalized radiances show some sensitivity among all SRAAs, especially with angles close to the sun where variability of up to $10 \%$ are found. A similar sensitivity study was shown in Frieß et al. (2006). The SA does not play a significant role in the simulation of either the RSP or radiances. Further discussion of the phase functions is presented in Sect. 3.3.2.

\subsection{Retrieval of AOD and $g$}

As shown before, maximal sensitivity towards AOD and aerosol phase function is achieved using the solar azimuth scan. The aim of this study is to develop a simple strategy in order to retrieve AOD and aerosol phase function $g$ while constraining SSA and SA. A simple method would be to compare the measurements with the RTM (Radiative Transfer Model) simulations and optimize the aerosol input parameters until we minimize the differences between measurements and simulations. An iterative approach for a single SRAA scan would require several hours to finalize. For a typical single day of measurements during the TCAP we collected at least 3500 spectra using only the azimuth scan. In this context, we believe that a flexible option is the creation of a lookup table (LUT) in which the RSP is simulated using geometry-related inputs and numerous aerosol optical properties.

We created the LUT based on different sets of SZA (20$90^{\circ}$ in steps of $10^{\circ}$ ) and adopted the positive SRAAs as measured by the 2-D-MAX-DOAS. The parameters that were fixed are the SSA, 0.98, based on findings by Müller et al. (2014) and Kassianov et al. (2015) during TCAP. The SA was set to 0.05 , representative of the land surface (obtained from the atmospheric transmission by the co-located MFRSR) and the aerosol extinction height (homogeneous box-height of $1.5 \mathrm{~km}$ ), though any other height would give similar results. We use typical pressure, temperature, and RH profiles (up to an altitude of $28 \mathrm{~km}$ ) measured from radiosondes during TCAP (Berg et al., 2016). Above $28 \mathrm{~km}$ the US Standard Atmosphere was used. The range of parameters that are important and were changed are the $\mathrm{AOD}_{430}$ and $g$. The range of AOD covered was from 0 up to $2.0 \mathrm{AOD}$ in steps of 0.02 . The range of $g$ covered was from 0.64 to 0.72 with increments of 0.02 . In order to compare with the measurements the LUT is interpolated to fine grid set points of AOD (in steps of 0.005) and to the average SZA during the measurements. The AOD and $g$ are varied to minimize the following expression:

$\chi^{2}=\sum_{i=1}^{N} \frac{\left[\mathrm{RSP}_{\mathrm{M}}-\mathrm{RSP}_{\mathrm{LUT}}(\mathrm{AOD}, g)\right]_{i}^{2}}{\mathrm{RSP}_{\mathrm{e}}^{2}} \rightarrow \min$,

where $\mathrm{RSP}_{\mathrm{M}}$ and RSP $\mathrm{RUT}_{\mathrm{T}}$ are the RSP (arb. units) measured and the simulated in the LUT. RSP $\mathrm{e}_{\mathrm{e}}$ is the final estimated RSP error in the measurements (see Sect. 3.3.1) and $N$ represents the number of SRAAs. A detailed representation of the sensitivity of RSP towards AOD using the SRAA scan and several SZA is shown in the Supplement (see Fig. S9). 


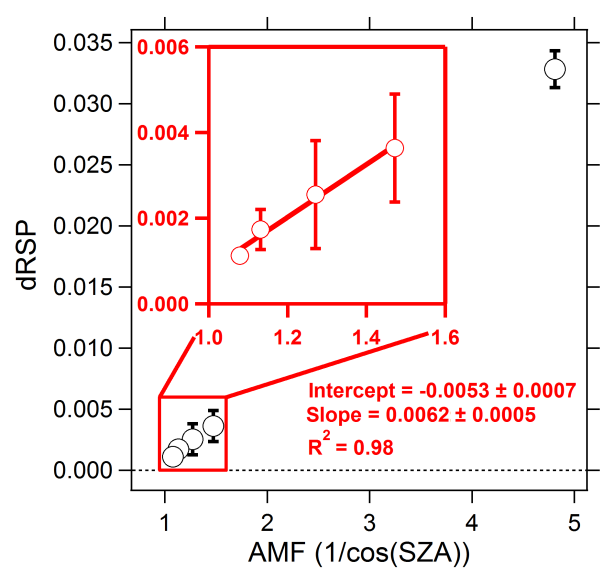

Figure 6. Direct sun $d R S P$ as a function of the air mass factor, $\mathrm{AMF}=1 / \cos (\mathrm{SZA})$. All direct sun spectra measured on 22 July 2012 were evaluated (SZA binned) relative to a direct sun reference spectrum measured at $\mathrm{SZA}=28^{\circ}$. The insert shows the magnification of the linear correlation plot used to quantitatively determine the offset at $\mathrm{AMF}=0$ (see text for details).

\subsection{Additional measurements}

The co-located MFRSR (Harrison et al., 1994) and the CIMEL sun photometer (Holben et al., 1998) complement our AOD observations at the TCAP ground site (see details in Table 1). The MFRSR measures total and diffuse solar irradiances at several channels to infer the direct solar radiation component (time resolution of $1 \mathrm{~min}$ ) while the sunsky photometer instrument measures the direct solar beam (time resolution of about $5 \mathrm{~min}$ ). While both instruments are radiometrically calibrated and work under different principles, a common feature is that they both use the direct sun transmission to derive AODs (Holben et al., 1998; Harrison et al., 1994). The $\mathrm{AOD}_{430}$ was calculated using the extinction Ångström exponent between the standard spectral bands of each instrument (see Table 1). The second-generation airborne High Spectral Resolution Lidar (HSRL-2), an improved version of the HSRL-1 (Hair et al., 2008), was deployed aboard the NASA Langley Research Center B200 King Air airplane. HSRL-2 measures particle backscatter coefficients at 355,532 , and $1064 \mathrm{~nm}$ and particle extinction coefficients at 355 and $532 \mathrm{~nm}$ (Müller et al., 2014). Similar to the sun photometer, the AOD at $430 \mathrm{~nm}$ was calculated using the extinction Ångström exponent between the standard wavelengths of 355 and $532 \mathrm{~nm}$. Atmospheric temperature and pressure profiles were provided by local radiosondes, which were launched four times a day at the ground site ( 00:00, 05:00, 17:00, and 23:00 UTC). The measurement vertical resolution of the sondes was about $10 \mathrm{~m}$, reaching a maximum altitude of about $28 \mathrm{~km}$. For this study, the closest radiosonde in time (17:00 UTC or 13:00 local standard time, $\mathrm{LST}=\mathrm{UTC}-4$ ) is used to prescribe the temperature, pressure, and relative humidity in the RTM.

\section{Results and discussions}

\subsection{Effect of the reference spectrum}

The direct sun geometry contains a small amount of RRS light and is hence not free of RSP contribution. In order to assess the RSP contribution in the direct sun spectra we use three different approaches: (1) a Langley plot type method, where the dRSP obtained with direct sun spectra as reference spectrum is plotted as a function of the SZA; (2) by interpolating the dRSP measured with small SRAAs to the $0^{\circ}$ (direct sun view); and (3) from RTM simulations. Figure 6 shows the linear correlation analysis between the direct sun dRSP (binned by SZA) measured on 22 July 2012, the low $\mathrm{AOD}_{430}$ case $(<0.13)$, and the air mass factor (AMF), $\mathrm{AMF}=1 / \cos (\mathrm{SZA})$. Several direct sun measurements were carried out between SZA of $22^{\circ}(\mathrm{AMF}=1.06)$ and $47^{\circ}$ $(\mathrm{AMF}<1.47)$ and only one at $78^{\circ}(\mathrm{AMF}=4.8)$. In order to quantitatively estimate the RSP in the reference we use the linear correlation analysis applied for SZA smaller than $50^{\circ}\left(R^{2}=0.98\right)$ (see inset plot in Fig. 6). The extrapolation to $\mathrm{AMF}=0$ yields the absolute value of the RSP contained in the reference spectrum (RSP value if there were no atmosphere), which is determined as $0.0053 \pm 0.0007$ by this method. The value of dRSP at high SZA $\left(78^{\circ}\right)$ is not considered here, since there is only one data point and the magnitude is significantly larger (likely due to atmospheric changes and increasingly distant air masses). To estimate the RSP contained in the reference with the second method we have analyzed closely the RSP measurements using the solar azimuth scan for SZA $<45^{\circ}$ and SRAA close to the sun $\left(\right.$ SRAA $\left.<40^{\circ}\right)$. The RSP decreases linearly for angles close to the sun and an interpolation to $0^{\circ}$ SRAA yields an RSP value of $0.0035 \pm 0.0005$. The third method consists in the simulation of the effective RSP in the direction of the sun following a three-step approach: (1) the radiance and the RSP are calculated for scattered Sunlight observations in the direction of the sun; (2) the radiance of the direct sun is calculated for the same direction (the RSP for the direct light is assumed as zero); (3) the effective RSP is calculated as the average RSP of both contributions (direct and scattered sun light) weighted by their respective radiances. The RSP derived following this procedure is 0.0038 , assuming AOD of 0.1 and $g$ of 0.68 . Interestingly, the RSP values are rather insensitive to changes in AOD, but a significant sensitivity exists towards a change in $g$ from 0.68 to 0.85 (roughly a factor 2 lower; see Table S1). We use the average of the three methods $(0.0042 \pm 0.0010)$ and add this offset to the measured dRSP to calculate the absolute RSP for comparison with RTM. For assessment of the RSP error, we propagate the $2 \sigma$ standard deviation $(0.0020)$ in the final uncertainty of $\mathrm{RSP}_{\mathrm{e}}$ and in error of AOD and $g$ products (see Sect. 3.3.1). 


\subsubsection{Comparing direct sun and zenith reference spectrum}

To assess the effect of the reference spectrum in the DOAS analysis of the dRSP we compare the dRSP results using the zenith and direct sun spectra as references; both spectra were recorded at SZA of $28^{\circ}$. Figure S10 shows the linear correlation of the dRSP analysis using each reference to analyze all spectra recorded for azimuth scans for SZA smaller than $70^{\circ}$ on 22 July 2012 . We find a strong linear correlation $\left(R^{2} \geq 0.99\right)$ and a slope close to unity $(1.023 \pm 0.001)$. The negative offset corresponds to $1.9 \%$ RSP contained in the zenith reference relative to the direct sun. Wagner et al. (2009b) estimated an RSP of $5 \pm 1 \%$ in the UV (350 nm) in the noon zenith sky reference by means of RTM simulations, using an AOD of 0.1 measured by a co-located instrument. The strength of the RSP depends on several factors such as wavelength, the atmospheric conditions (aerosol and cloud optical properties), and the geometry of measurements. The dRSP in Fig. S10 is color coded by SRAA. The strong SRAA dependency reflects the sensitivity of RSP to atmospheric scattering processes. The dRSP decreases for angles close to the sun and increases for larger SRAAs. When using the zenith sky as reference the dRSP obtained would be negative for SRAA $<50^{\circ}$ and there would be a general negative bias of $1.9 \%$. Of all possible viewing directions accessible with ground-based measurements the direct sun observation is the least affected by RRS. In addition, direct sun observations measured with the same instrument ensure that the spectral resolution and sampling used in the DOAS analysis of all spectra are the same. Using a zenith spectrum from the same measurement sequence would make the results dependent on the RSP contained in the reference spectrum. The minimization of Eq. (1) would require an additional simulation of the RSP in the reference for all AODs, i.e., a separate LUT for each sequence scan because the AOD in the reference spectrum would be unknown. In principle this approach should be feasible, but it is less direct than the approach chosen in this work. Use of a zenith reference spectrum may help the dRSP precision, but it also adds a source for potentially significant offsets that can limit accuracy.

\subsubsection{Calculating references from high-resolution spectra}

In principle, high-resolution solar spectra (e.g., Chance and Kurucz, 2010) should provide a viable alternative to direct sun measurements as reference spectra to retrieve absolute RSP. Such high-resolution spectra need to be convoluted with the instrument slit function prior to their use as reference spectrum in the DOAS analysis of RSP. We have tested this approach and used high-resolution literature data as a reference spectrum for the analysis of the azimuth scan spectra (1 $\mathrm{s}$ integration time), and we found large fitting residuals $(\mathrm{RMS} \sim 0.01)$ that have a strong effect on the retrieved
RSP values, suggesting that this approach is currently of limited value in practice. The causes are likely due to a combination of reasons, including imperfect knowledge about the wavelength-dependent instrument line shapes, numerical artifacts and assumptions made during convolution, nonlinearity of detectors, and small differences in wavelength calibration. Notably, measuring the direct sun reference spectrum in the same instrument as the scattered light spectra inherently accounts for these factors.

\subsection{Effect of aerosol inhomogeneity}

The RTM simulation of RSP and $R_{\text {norm }}$ considers aerosol to be uniformly distributed around the measurement site. To assess if the air mass probed is inhomogeneous we compare quantitatively the symmetry of the $I_{\text {norm }}$ measurements to the left and right side of the sun's disk. The quantitative analysis of symmetry is defined by the angular asymmetry factor parameter $\left(\mathrm{AFP}_{I_{\mathrm{norm}}}\right)$ :

$\mathrm{AFP}_{I_{\text {norm }}}=\frac{\left(I_{\text {norm }}^{L}-I_{\text {norm }}^{R}\right)}{\left(I_{\text {norm }}^{L}+I_{\text {norm }}^{R}\right) \cdot 0.5}$,

where $I_{\text {norm }}^{L}$ and $I_{\text {norm }}^{R}$ are the left and right side measurements of the $I_{\text {norm }}$ (counts s ${ }^{-1}$ ) obtained with the almucantar scan. The $\mathrm{AFP}_{I_{\text {norm }}}$ on 17 and 22 July 2012 are shown in the form of a polar plot in Fig. S11. Over the past few years, CIMEL sun photometers have used a similar approach as a consistency check to reject pairs of data that exceed $20 \%$ difference and under uniformity the retrieval inversion of aerosol microphysical properties is applied (Holben et al., 1998). Both days show $\mathrm{AFP}_{I_{\text {norm }}}<10 \%$, indicating a high degree of symmetry. In general, the random noise in $\mathrm{AFP}_{I_{\text {norm }}}$ is on the order of $0.25 \%$. If the $\mathrm{AFP}_{I_{\text {norm }}}$ shows consistent positive and/or negative values among several SRAAs this may indicate aerosol inhomogeneity. For example, the increase in AOD at $\sim 12: 00$ LST on 17 July was accompanied by an average $\mathrm{AFP}_{I_{\text {norm }}}$ of $+2.7 \%$ for the corresponding solar azimuth scan and maximum $\mathrm{AFP}_{I_{\text {norm }}}$ of $+10 \%$ at $105^{\circ}<\mathrm{SRAA}<145^{\circ}$, indicating higher AOD in the southwesterly direction. Ortega et al. (2016) examined the aerosol extinction inhomogeneity using HSRL-2 data from overpasses above the TCAP ground site and found that the AOD varied by about $10 \%$ across the site at $\sim 13: 00$ LST on 17 July 2012. By contrast, on 22 July there were no significant differences visible in the HSRL-2 data, and the symmetry remained all day with average $\mathrm{AFP}_{I_{\text {norm }}}$ of $0.19 \%$ and a standard deviation of $3.3 \%$.

\subsection{Uncertainty of RSP retrievals of AOD and $g$}

\subsubsection{RSP retrieval of AOD: maximal sensitivity at low AOD}

Figure 7 shows the simulated RSP in the solar azimuth scan as a function of AOD. In order to quantitatively assess the 

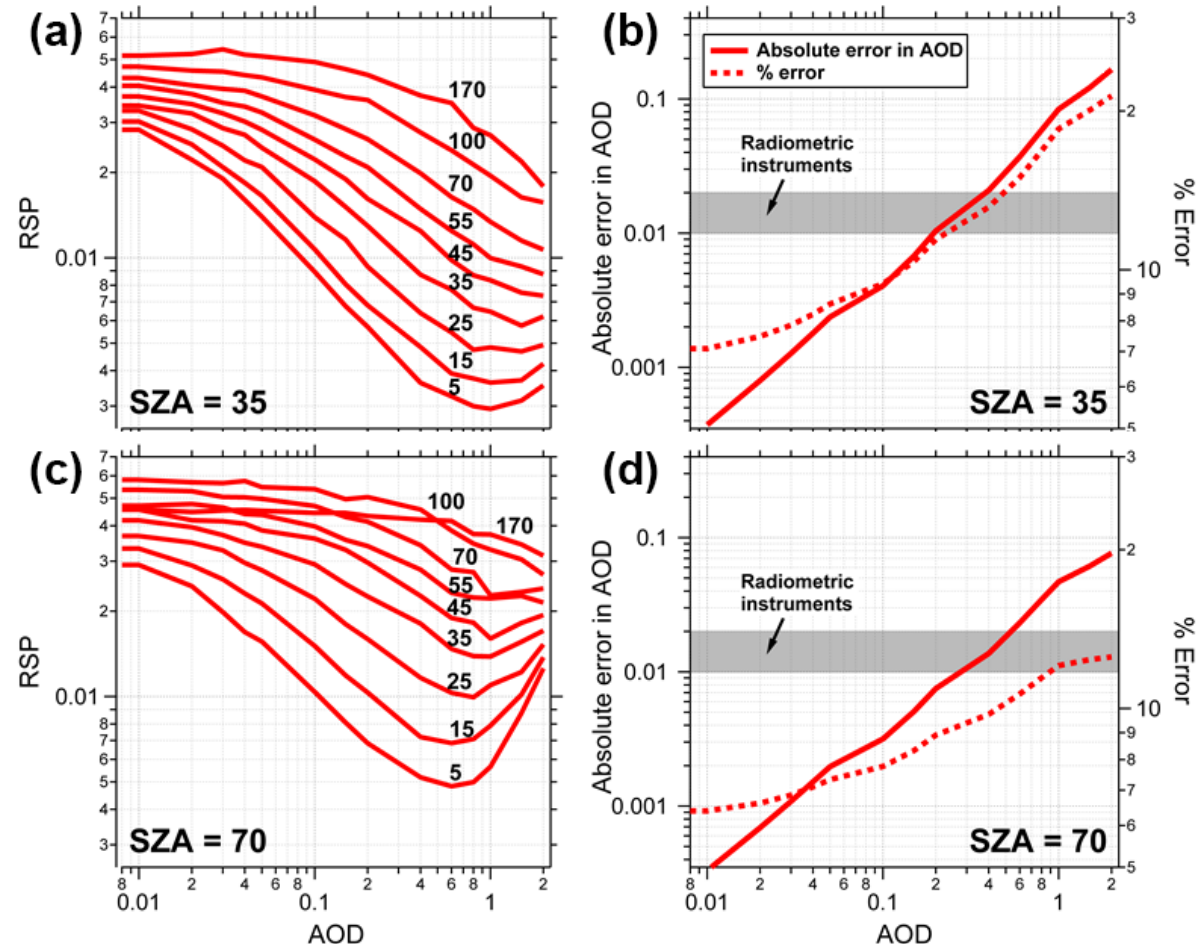

Figure 7. Simulated RSP as a function of AOD for $5^{\circ}<\mathrm{SRAA}<100^{\circ}$ at (a) SZA $=35^{\circ}$ and (c) SZA $=70^{\circ}$. Additional parameters are $g=0.72, \mathrm{SA}=0.05, \mathrm{SSA}=0.98$. (b, d) Absolute error in AOD and percentage error calculated with Eq. (3) (see text for details). An AOD error range of $0.01-0.02$ is indicated with the gray shadow area. A value of 0.01 is typical of newly radiometrically calibrated instruments.

response through different sets of AOD a linear correlation analysis have been calculated for several subsets of AODs and the results are shown in the Table S2. The highest response in RSP to changes in AOD is observed at low AOD, i.e., under conditions when Rayleigh scattering extinction dominates over aerosol extinction. The sensitivity is highest for small SRAAs. A change of 0.01 AOD when molecular scattering dominates $\left(\mathrm{AOD}_{430}<0.1\right)$ yields a considerable decrease in the RSP $(\triangle \mathrm{RSP}=0.004)$ for SRAA $<35^{\circ}$. This change is significantly greater than the DOAS fit error of 0.0018 presented in Sect. 2.3. The sensitivity decreases for SRAA $>35^{\circ}$, but the same change in AOD yields a significant (measurable) RSP response up to a SRAA of $70^{\circ}$. In contrast, the sensitivity towards changes in AOD is weaker for AOD greater than 0.3, especially for low SZA, and for small SRAAs. This is likely due to the dominance of aerosol scattering and few molecular scattering events. While the reduced sensitivity can in principle be circumvented by evaluating larger SRAAs, such analysis puts more stringent criteria on aerosol homogeneity. The absolute error in the AOD for any particular SRAA $\left(\mathrm{AOD}_{\mathrm{e}}^{i}\right)$ was calculated as

$\mathrm{AOD}_{\mathrm{e}}^{i}=\left(\frac{\mathrm{RSP}_{\mathrm{e}}}{\mathrm{RSP}^{i}}\right) \times \mathrm{AOD}$,

where $\mathrm{RSP}^{i}$ is the RSP in the $i$ th SRAA and $\mathrm{RSP}_{\mathrm{e}}$ is calculated as the error in the RSP propagated from the DOAS mea- sured RSP error $(\sim 0.0018)$ and the error in the estimation of the RSP in the reference (0.0024). Assuming the errors of the measurement to be additive, the final $\mathrm{RSP}_{\mathrm{e}}$ is about 0.0028. Equation (3) is applied to all SRAAs and sets of AODs from Fig. 7a. Figure 7b shows the calculated absolute error in $\mathrm{AOD}\left(\mathrm{AOD}_{\mathrm{e}}\right)$ using all elements from Fig. 7a and weighted as follows:

$\mathrm{AOD}_{\mathrm{e}}=\frac{\sum\left(\frac{\mathrm{AOD}_{\mathrm{e}}^{i}}{\mathrm{RSP}_{\mathrm{e}}}\right)^{2}}{\sum\left(\frac{1}{\mathrm{RSP}_{\mathrm{e}}}\right)^{2}}$.

The weighted RSP relative error $\left(\frac{\mathrm{RSP}_{\mathrm{e}}}{\mathrm{RSP}^{i}}\right)$ following the same approach is also shown in percentage in Fig. 7b. Under high AOD conditions $(\sim 0.4)$ the absolute $\mathrm{AOD}_{\mathrm{e}}$ is 0.02 . The $\mathrm{AOD}_{\mathrm{e}}$ decreases significantly for $\mathrm{AOD} \leq 0.1$, with uncertainties of about 0.004 at AOD of 0.1 and 0.0025 at AOD of 0.05 .

As mentioned before the information content on aerosols using the solar azimuth scan is enhanced at large SZA when RSP values are larger. At SZA $=70^{\circ}$ (Fig. 7c), the errors decrease further for low AOD as is illustrated in Fig. 7d. The $\mathrm{AOD}_{\mathrm{e}}$ is $0.014,0.003$, and 0.002 for an AOD of 0.4, 0.1, and 0.05 , respectively. The error scales roughly with $\cos (\mathrm{SZA})$, indicating that the highest sensitivity of RSP-based AOD retrievals is at high SZA and low AOD. 

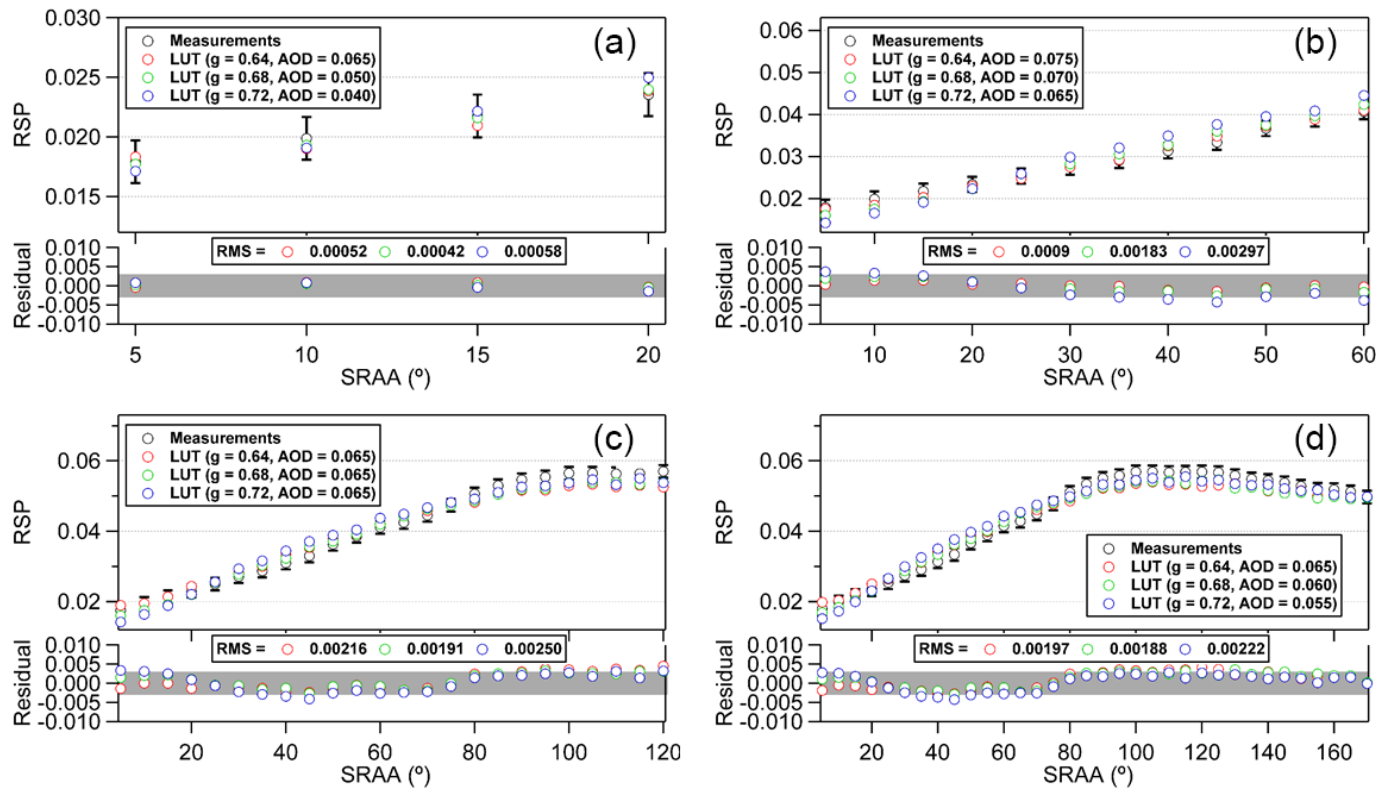

Figure 8. Comparison of measured RSP (black open circles) and simulated RSP (open circles) with the LUT using three different $g$ (red: $g=0.64$; green: $g=0.68$; blue: $g=0.72$ ). The examples shown here represent the best fit that minimizes Eq. (1) for different ranges of SRAA: (a) $5-20^{\circ}$, (b) $5-60^{\circ}$, (c) $5-120^{\circ}$, and (d) $5-170^{\circ}$ SRAA. The retrieved AOD in each case is indicated in the labels.

\subsubsection{Aerosol phase function}

As shown in Fig. 5, the phase function parameter $g$ has the strongest effect on the simulated RSP for small SRAAs. A decrease of $g$, i.e., decrease of aerosol forward scattering probability, leads to an increase of the RSP due to a higher contribution of molecular scattering at this direction. The radiances also show a significant sensitivity towards $g$ for small SRAAs, as previously shown by Frieß et al. (2006). For a fixed AOD and a change in $g$ of \pm 0.04 the RSP difference is about 0.03 for a SRAA of $5^{\circ}$, which is 2 times greater than the RSP error. In general, measurements at small SRAAs carry most information and are highly recommended (Holben et al., 1998; Frieß et al., 2006). In addition, the quality of the retrieval of $g$ is expected to improve for high SZAs when there is an increase in the information content of the scattering angle coverage (Torres et al., 2013; Dubovik et al., 2000).

\subsection{Comparison of measurements and simulations}

We compare simulated and measured RSP for several SRAA ranges in Fig. 8. The example shown in Fig. 8 is obtained by applying the retrieval approach explained in Sect. 2.5 for the solar azimuth scan $\left(\mathrm{SZA}=66.5^{\circ}\right)$ on 22 July 2012 . Four sets of SRAAs are used: (a) $5-20^{\circ}$, (b) $5-60^{\circ}$, (c) $5-120^{\circ}$, and (d) $5-170^{\circ}$. Three values for $g$ are used to show the sensitivity towards the phase function. The AOD retrieved with each $g$ is shown in the label box. The residuals, defined as the difference between measured and simulated RSP (minimizing Eq. 1), are shown in the bottom panel below each compari- son. The gray shaded area (behind the residuals) represents the RSP error $( \pm 0.0028)$ defined before. The computed RMS errors (RMSEs) are also shown. The comparison of the RSP constrained by few SRAAs $\left(<20^{\circ}\right.$, Fig. 8 a) shows that all the residuals lie within the error bars independently of $g$. However, the variability of the retrieved AOD is significant for each $g$ and maximum $\triangle \mathrm{AOD}$ of 0.025 is obtained. When using more SRAAs (Fig. 8b-d) the spread in AOD values is reduced. The maximum $\triangle \mathrm{AOD}$ obtained using either 5$60^{\circ}, 5-120^{\circ}$, or $5-170^{\circ}$ SRAAs is 0.010 . Significant residuals (greater than the RSP error) are obtained for $g$ larger than 0.68 . The residuals obtained with the $g$ of 0.64 are always within the error bars of the measured RSP, indicating that this $g$ (for SRAA $<40^{\circ}$ ) is in excellent agreement with the $g$ of 0.65 reported by the CIMEL sun photometer close to this time. This further suggests that SRAAs close to the sun are needed and essential in order to maximize the sensitivity of the aerosol phase functions.

\subsection{Optimized observing strategy}

We have optimized a retrieval strategy such that at high SZA $\left(>50^{\circ}\right)$ we use SRAAs in the range of $5-60^{\circ}$, and for smaller SZA we use the full azimuth scan $\left(5^{\circ}<\mathrm{SRAA}<170^{\circ}\right)$. This was motivated by the fact that for $5^{\circ}<\mathrm{SRAA}<60^{\circ}$ the AOD and $g$ are stable and show the minimal RMSE and maximal information content at high SZA for this range. However, less information content is achieved at low SZA and more SRAAs are needed. This optimization may be important in the presence of broken clouds. In this case, as long as there 

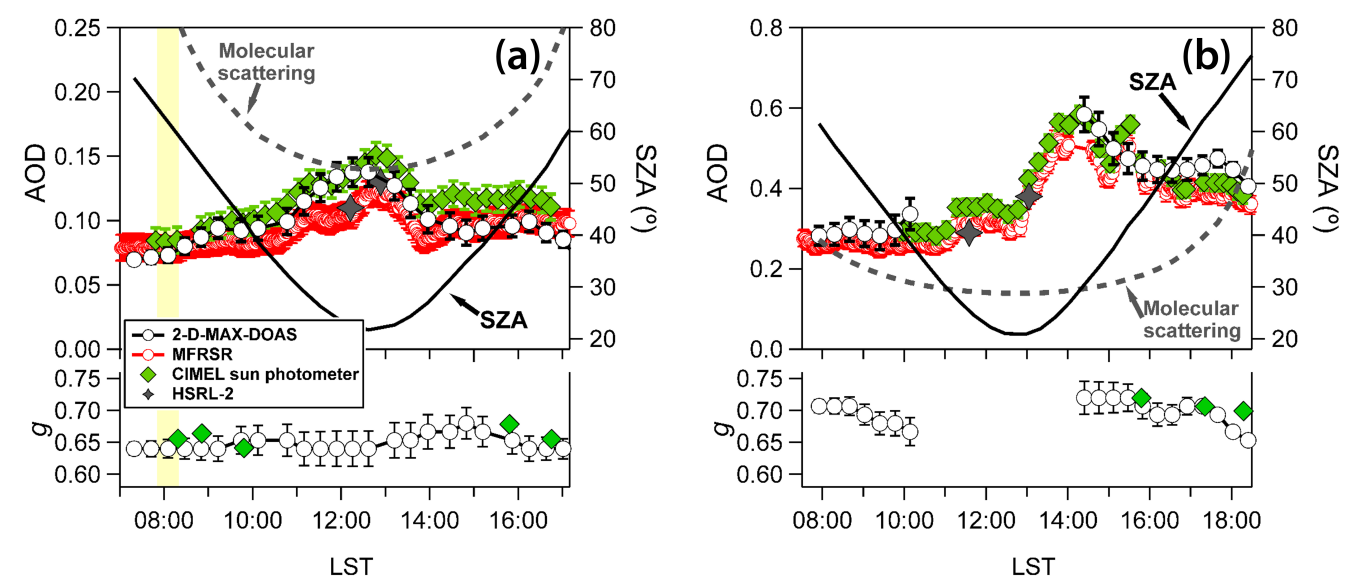

Figure 9. Time series of AOD comparing the 2-D-MAX-DOAS with MFRSR, CIMEL sun photometer, and HSRL-2 under (a) low AOD case on 22 July and (b) high AOD on 17 July. The dashed gray line represents the molecular optical depth. The retrieved $g$ from 2-D-MAX-DOAS $(430 \mathrm{~nm})$ and CIMEL $(440 \mathrm{~nm})$ are shown in the bottom plot. The yellow shading in (a) represents the time period used in the example of Fig. 8.

is homogeneity for SRAA $<60^{\circ}$ the retrieval strategy presented here may yield good results.

TCAP represented the first deployment of the CU 2-DMAX-DOAS instrument. The geometry of measurements was motivated by retrieving simultaneously trace gas and aerosol extinction profiles by means of the EA scan and by testing the solar azimuth scan for the first time (Table 2). The acquisition time of the solar azimuth scan was 2 min. However, the time resolution of the retrieved products is about 20 min due to the $85 \%$ duty cycle of the EA scan in the single repetition of both EA and solar azimuth scan. The fast mode of measurements in the almucantar limits the retrieval of many typical DOAS species such as the oxygen dimer $\left(\mathrm{O}_{2}-\mathrm{O}_{2}\right.$, or $\left.\mathrm{O}_{4}\right)$ and other trace gases (such as $\mathrm{NO}_{2}$, $\mathrm{HCHO}, \mathrm{CHOCHO}$, etc). Incrementing the time resolution in the solar azimuth scan would mean that $\mathrm{O}_{4}$ could be measured and have an additional piece of information in the retrieval of aerosol optical/microphysical properties. Future deployments may consider a combination of SRAA scans with longer integration time to also obtain trace gases and EA scans for a subset of SRAAs to obtain trace gas vertical profiles. In addition, future deployments with 2-D capabilities might consider the solar principal plane sky geometry, which is similar to the almucantar scan but in the principal plane of the sun (see Holben et al., 1998). This geometry would be very similar to the typical off-axis scan, i.e., high sensitivity towards the lower part of the atmosphere. In addition, SRAAs would be measured giving information about phase functions. Furthermore, a future deployment may dedicate a full day to direct sun observations in order to apply the Langley plot to more SZA, ideally during constant diurnal AOD conditions such as in Mauna Loa, HI.

\subsection{AOD comparison from DOAS with CIMEL sun photometer, MFRSR, and HSRL-2}

Figure 9 compares the diurnal variability of $\mathrm{AOD}_{430}$ and $g$ with independent measurements by MFRSR, CIMEL sun photometer, and HSRL-2 instruments for (a) 22 July (low AOD case) and (b) 17 July (high AOD case) 2012. The molecular scattering optical depth represented with the discontinuous gray line is calculated with the method reported by Bodhaine et al. (1999) using the temperature and pressure profiles from the local radiosonde (launched at 13:00 LST). Considering a diurnal direct sun geometry the molecular scattering optical depth is weighted by the air mass factor $1 / \cos (\mathrm{SZA})$. On 22 July the retrieved aerosol $\mathrm{AOD}_{430}$ is below the molecular scattering regime all of the day for MFRSR, DOAS, and HSRL-2 and most of the time for the CIMEL sun photometer. Under these conditions the uncertainties of the AOD retrieved from the solar beam extinction approach, i.e., MFRSR and CIMEL sun photometer, might be greater than 0.01 AOD, which is a typical error after calibration (Holben et al., 1998; Harrison et al., 1994). We have adopted this ideal error of 0.010 AOD for the MFRSR and CIMEL sun photometer in Fig. 9a. The error bars of the 2D-MAX-DOAS are those discussed in Sect. 3.3.1. In general, the errors are smaller at high SZA, as discussed in Sect. 3.3.1, and the largest errors are $\sim 0.012$ at noon. The comparison of the $\mathrm{AOD}_{430}$ retrieved by DOAS compares well and is generally within the combined error bars with the other measurements. The comparison is best in the morning, and DOAS agrees better with the MFRSR throughout the day; there is only marginal agreement with the CIMEL sun photometer in the afternoon. At noon, there is a small increase in $\mathrm{AOD}_{430}$ of about 0.05 and the response of this change is greater for the 2-D-MAX-DOAS than for the MFRSR and sun photometer, 


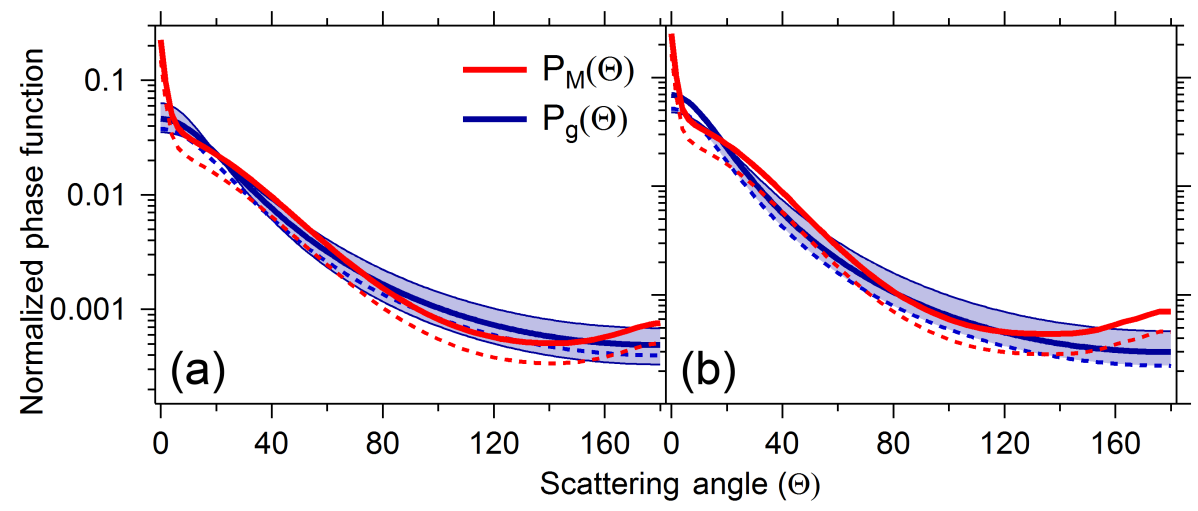

Figure 10. Comparison of area-normalized phase functions under (a) low AOD (22 July 2012 at 8:50 LST) and (b) high AOD (17 July 2012 at 15:50 LST). Solid and dashed lines represent the normalization between 5 and 180 and 0 and $180^{\circ}$, respectively. The blue shaded represent a typical error in $g$ of $10 \%$ (shown only for the solid lines).

likely due to maximum sensitivity to small changes in AOD. A power outage inside the seatainer restricted measurements after 17:30 LST.

The average diurnal difference of $\mathrm{AOD}_{430}$ (relative to the 2-D-MAX-DOAS) on 22 July is $+0.0199 \pm 0.014$ (CIMEL), $+0.003 \pm 0.019$ (MFRSR), and $-0.011 \pm 0.014$ during the overpass of the HSRL-2. The AOD 430 measured by HSRL-2 during two overpasses is slightly lower than the $\mathrm{AOD}_{430}$ measured by the CIMEL sun photometer and agrees closely in one instance with the 2-D-MAX-DOAS, and the closest agreement is observed for MFRSR. Note that the HSRL AOD values correspond to the layer between the surface and about $7 \mathrm{~km}$. In general, $90-95 \%$ of the aerosol extinction is estimated to be below the $\sim 7 \mathrm{~km}$. The average diurnal difference in $\mathrm{AOD}_{430}$ shows that the CIMEL sun photometer is 0.017 greater than MFRSR. In general a good agreement is reflected in the linear correlation analysis between the 2D-MAX-DOAS and CIMEL sun photometer - DOAS $_{\mathrm{AOD}}=$ $-(0.013 \pm 0.010)+(0.96 \pm 0.09) \times \operatorname{CIMEL}_{\mathrm{AOD}}\left(R^{2}=0.82\right)$ - between 2-D-MAX-DOAS and MFRSR - DOAS $_{\mathrm{AOD}}=$ $-(0.029 \pm 0.020)+(1.32 \pm 0.21) \times$ MFRSR $_{\text {AOD }}$ $\left(R^{2}=0.64\right) \quad-$ and between CIMEL sun photometer and MFRSR - CIMEL $_{\mathrm{AOD}}=-(0.028 \pm 0.009)+(1.45 \pm$ $0.10) \times$ MFRSR $_{\text {AOD }} \quad\left(R^{2}=0.91\right)$. Notably, the offset is larger than 0.02 in some instances, highlighting the importance of instrument comparisons under low AOD conditions.

On 17 July the $\mathrm{AOD}_{430}$ reached values of 0.6 at noon (Fig. 9b). The high AOD and the inhomogeneity identified with AFP values larger than 10\% from 11:00 to 14:00 LST limited the retrieval of AOD and $g$ from the 2-D-MAXDOAS. As shown in Fig. 7 the RSP decreases significantly at high AOD and low SZA likely due to dominance of multiple aerosol forward scattering. On this day averaged RSP values obtained with the solar azimuth scans from $\sim 11: 00$ to 14:00 were similar to the RSP error limiting the analysis. This could be circumvented in the future by conducting almucan- tar scans at a lower EA. Under conditions when a retrieval is warranted, the comparison of the difference in $\mathrm{AOD}_{430}$ (relative to the 2-D-MAX-DOAS) is $-0.027 \pm 0.03$ (CIMEL) and $+0.005 \pm 0.027$ (MFRSR). The AOD from CIMEL sun photometer is $0.035 \pm 0.015$ greater than that from MFRSR. The linear correlation between the 2-D-MAX-DOAS and CIMEL sun photometer is $\mathrm{DOAS}_{\mathrm{AOD}}=-(0.017 \pm$ $0.034)+(0.95 \pm 0.08) \times$ CIMEL $_{\mathrm{AOD}} \quad\left(R^{2}=0.88\right), \quad$ between 2-D-MAX-DOAS and MFRSR is DOAS $_{\mathrm{AOD}}=$ $-(0.025 \pm 0.027)+(1.00 \pm 0.07) \times$ MFRSR $_{\mathrm{AOD}}$ $\left(R^{2}=0.91\right)$, and between CIMEL sun photometer and MFRSR is CIMEL $_{\mathrm{AOD}}=-(0.020 \pm 0.015)+(1.03 \pm$ $0.04) \times \operatorname{MFRSR}_{\mathrm{AOD}}\left(R^{2}=0.97\right)$.

Clearly under high AOD conditions the maximum AOD diurnal difference of $\sim 0.027$ accounts for less than $5 \%$ of the AOD. However, the diurnal differences between instruments under low AOD account $(\sim 0.02)$ for about $20 \%$ of the AOD. Overall good agreement is reflected in the linear regression analysis of pooled data from both case study days: $\mathrm{DOAS}_{\mathrm{AOD}}=$ $-(0.019 \pm 0.006)+(1.03 \pm 0.02) \times$ CIMEL $_{\mathrm{AOD}}$

$\left(R^{2}=0.98\right), \quad$ DOAS $_{\mathrm{AOD}}=-(0.006 \pm 0.005)+(1.08 \pm$ $0.02) \times$ MFRSR $_{\mathrm{AOD}} \quad\left(R^{2}=0.98\right), \quad$ and CIMEL $_{\mathrm{AOD}}=$ $(0.013 \pm 0.004)+(1.05 \pm 0.01) \times \operatorname{MFRSR}_{\mathrm{AOD}}\left(R^{2}=0.99\right)$.

\subsection{Aerosol phase functions}

The simplification of the aerosol phase function by the HG parameterization may not reflect realistic aerosol phase functions. A technical limitation exists in that our RTM only uses the HG simplification and more rigorous aerosol phase functions, e.g., Mie phase functions, are not handled. We have conducted additional sensitivity studies using RTM in an attempt to bind the effect of Mie phase functions. The aerosol phase function was calculated using the HG approximation, $P_{\mathrm{HG}}(\Theta)$ (Henyey and Greenstein, 1941), and compared with Mie calculations constrained from the co-located sun pho- 
tometer, $P_{\mathrm{Mie}}(\Theta)$. The $P_{\mathrm{HG}}(\Theta)$ is calculated from the following analytical equation:

$$
P_{\mathrm{HG}}(\Theta)=\frac{1}{4 \pi} \frac{1-g^{2}}{\left(1+g^{2}-2 g \times \cos (\Theta)\right)^{3 / 2}},
$$

where $\Theta$ is the scattering angle and $g$ the asymmetry parameter. Figure 10 compares the area-normalized phase functions under (a) low and (b) high AOD conditions. The area normalization is carried out using scattering angles of $5^{\circ}$ and larger (i.e., $5-180^{\circ}$, solid lines) to roughly resemble our measurements/retrieval conditions and dashed lines represent the normalization between 0 and $180^{\circ}$. The red lines are the retrieved $P_{\text {Mie }}(\Theta)$ reported in the AERONET website (version 2.0) measured close in time with our RSP-based retrievals, and the blue lines are calculated using Eq. (5). The deviations between $P_{\mathrm{HG}}(\Theta)$ and $P_{\mathrm{Mie}}(\Theta)$ are most prominent at small scattering angles $\left(\Theta<5^{\circ}\right)$ and, to a lesser extent, also at large scattering angles $\left(\Theta>150^{\circ}\right.$, only at high AOD). For most scattering angles, and under high and low AOD conditions, the comparison is within the $10 \%$ error in $g$. Larger differences are found in scattering angles smaller than $10^{\circ}$ and the agreement improves at large scattering angles with the normalization between 0 and $180^{\circ}$. We thus attribute the fact that a simplistic phase function can explain our RSP measurements reasonably well to the fact that we did not probe small scattering angles $\left(\Theta<5^{\circ}\right)$. RTM that represent Mie phase functions are desirable. However, also Mie phase functions present an approximation of the true phase function, i.e., assume particles to be spheres of a certain internal symmetry. RSP measurements at scattering angles smaller $5^{\circ}$ are potentially very interesting because they hold potential to evaluate Mie theory in new ways.

The determination of the RSP in the reference by method 2 (see Sect. 3.1) assumes a smooth transition of RSP from scattered sunlight to the direct solar beam. Further RTM simulations were carried out to test this smoothness of RSP. We have tried to circumvent the RTM limitation by approximating the Mie phase function shown in Fig. 10 with a combination of different $g$, then use these values to simulate the RSP for SRAA $<10^{\circ}$ and the direct sun component. Figure S12 shows the comparison of the area-normalized phase function calculated with a combination of several $g\left(P_{\mathrm{HG}}^{\mathrm{c}}(\Theta)\right)$ with $P_{\text {Mie }}(\Theta)$ for scattering angles $<11^{\circ}$. The $g$ values needed are also shown. Note that these $g$ values are not realistic and are used simply to approximate the results of a more realistic Mie phase function shape over a limited range of forward scattering angles. Figure S13 shows the simulated RSP. The value of scattering angle equals zero corresponds to the effective RSP in the direct sun geometry. Interestingly, the transition is smooth only for the approximated Mie phase function (larger $g$ ), while a steep gradient is observed in the HG approximation (small $g$ ). Based on these results method 2 is valid to determine the RSP in a direct sun reference spectrum in the atmosphere. Whether models can be used to es- timate RSP in the direct solar beam depends on the assumptions about the aerosol phase function. Future research will need to develop more sophisticated RTM that represent Mie phase functions to test RSP predictions at small SRAAs, and measurement hardware to provide robust capabilities for RSP measurements at small SRAAs, in order to establish whether method 2 applies more broadly. For HG a smooth transition of the RSP between measurements of scattered and direct sun light cannot be expected. However, in the atmosphere the HG may not be good approximation, and the pronounced forward scattering of a Mie phase function adds a significant weight to the RSP scattered radiance. This has the effect of smoothing the transition of the RSP between measurements of scattered and direct sun light.

\subsection{Context with literature: advantages and limitations}

According to Holben et al. (1998) the AOD uncertainty of newly calibrated sun photometers is \pm 0.01 for typical visible wavelengths and \pm 0.02 for shorter wavelengths. In particular, the error in AOD becomes highly sensitive to the calibration error at low AOD. For example, for $\mathrm{AOD}_{440}<0.05$ and $5 \%$ calibration error the AOD uncertainty can reach $44 \%$. In contrast, the error in AOD decreases dramatically for the same calibration error when solar scattering measurements are used (Holben et al., 1998). Our innovative retrieval strategy for AOD and $g$ is based on solar scattered light but circumvents the calibration uncertainty outlined above and provides robust measurements under low AOD conditions. Our measurements are inherently calibrated, i.e., do not require radiance calibration which is subject to drift, and need frequent sensor attention during field operation. The RSP-based retrievals only rely on relative radiance measurements in the SRAA and hyperspectral domain, which makes them particularly useful for long-term observations in remote environments.

The diurnal error in AOD of direct sun transmission measurements is also subject to the optical path through the Earth's atmosphere. In general, the nominal error in AOD will change with the air mass factor $(\cos (\mathrm{SZA}))$ and potentially needs to be scaled accordingly, leaving smaller errors at high SZA (Sinyuk et al., 2012). One important advantage of RSP-based retrievals is that the aerosol information content is enhanced at low AOD. RSP constraints to column aerosol optical properties are complementary to $\mathrm{O}_{2}-\mathrm{O}_{2}$ measurements that are widely used to infer information about clouds and aerosols (Baidar et al., 2013; Gielen et al., 2014; Wagner et al., 2014; Ortega et al., 2016; Volkamer et al., 2015). The synergistic use of RSP and $\mathrm{O}_{2}-\mathrm{O}_{2}$ holds great potential to better assess profile and column properties of aerosols and clouds and currently remains largely unexplored. 


\section{Conclusions and outlook}

In this work we present a detailed analysis of RRS using direct sun and solar almucantar measurements of scattered solar photons by the CU 2-D-MAX-DOAS instrument (see Part 1; Ortega et al., 2015). The rapid solar azimuth scan, i.e., integration time of $1 \mathrm{~s}$ and total acquisition time of $\sim 2 \mathrm{~min}$ to measure from -180 to $180^{\circ}$ SRAA in steps of $5^{\circ}$ relative to the sun, provides robust means to simultaneously retrieve AOD and the column-integrated aerosol phase function (simplified by the asymmetry parameter, $g$ ). We conclude the following.

- Measurements of RSP have maximum sensitivity towards retrieving AOD and $g$ under molecular scattering conditions. This is demonstrated with RTM simulations of the RSP using diurnal solar azimuth geometry. The highest sensitivity towards both $g$ and AOD is achieved if using small SRAAs $\left(\leq 5^{\circ}\right)$. RSP measurements at SRAA $<5^{\circ}$ hold potential to evaluate Mie theory in new ways.

- The error in the RSP-based retrieval of AOD and $g$ is limited by the uncertainty about RSP contained in the reference spectrum. We minimize the error by retrieving near-absolute RSP using a direct sun reference spectrum recorded with the same instrument. The direct sun spectrum is also affected by RRS. We estimate $\mathrm{RSP}_{\mathrm{DS}}=$ $0.40 \pm 0.20 \%$, which is $\sim 6$ times smaller compared to $\mathrm{RSP}_{\text {zenith }}=2.34 \pm 0.22 \%\left(\mathrm{SZA}=28^{\circ}, \mathrm{AOD}_{430}=\right.$ 0.11). Direct sun observations at low SZA systematically minimize RSP and are most valuable for accurate AOD and $g$ retrievals.

- RSP-based retrievals of AOD and $g$ have higher sensitivity at high SZAs and low AOD. This is complementary to existing techniques that operate on solar transmission. The absolute error are about $0.02,0.004$, 0.0025 , and 0.0005 for $\mathrm{AOD}_{430}$ of $0.4,0.1,0.05$, and 0.01 , respectively (4-5\% relative error), at $\mathrm{SZA}=35^{\circ}$. The errors decrease with increasing SZA, and absolute errors are $0.014,0.003,0.002$, and 0.0004 for $\mathrm{AOD}_{430}$ of $0.4,0.1,0.05$, and 0.01 , respectively (3-4\% relative error), at $\mathrm{SZA}=70^{\circ}$.

- The RSP retrieval of AOD and $g$ is inherently calibrated, since it relies only on relative intensity changes that are measured in the hyperspectral domain and at various SRAAs. Combined with the high sensitivity at low AOD and high SZA, measurements of RSP are particularly useful to conduct long-term time series measurements in remote environments, such as the arctic, or remote ocean environments at tropical latitudes.

Retrievals based on RSP measurements at a subset of SRAAs hold potential to measure AOD under broken cloud conditions. Clear-sky and broken cloud conditions can be identified using the color index, and AOD retrievals under such conditions warrant further study. The retrieval strategies may be optimized by conducting azimuth scans with longer integration time, at solar EAs and lower EAs, and by conducting EA scans for a larger subset of SRAAs to simultaneously measure azimuth distributions and vertical profiles of trace gases. 2-D-MAX-DOAS measurements in the solar principal plane sky geometry (similar to the almucantar scan) would further increase the sensitivity towards the lower part of the atmosphere.

\section{Data availability}

The CIMEL sun photometer data were collected by the US Department of Energy as part of the ARM Program Climate Research Facility and processed by AERONET (http: //aeronet.gsfc.nasa.gov/). Data collected during the TCAP field experiment, including HSRL-2 and MFRSR, are available from the ARM data archive (www.archive.arm.gov). The DOAS data can be accessed through the Volkamer group website (http://ciresgroups.colorado.edu/volkamergroup/).

\section{The Supplement related to this article is available online at doi:10.5194/amt-9-3893-2016-supplement.}

Acknowledgements. The instrument was developed with support from the NSF-CAREER award ATM-0847793; US Department of Energy (DOE) award DE-SC0006080 supported the TCAP deployment (RV). Ivan Ortega is the recipient of a NASA Earth Science graduate fellowship. Larry Berg is supported by the DOE Atmospheric System Research (ASR) Program. The Pacific Northwest National Laboratory is operated by Battelle Memorial Institute under contract DE-AC06-76RLO 1830. Support for the HSRL-2 light operations during TCAP was provided by the DOE ARM program: Interagency Agreement DE-SC0006730. We are grateful to Tim Deutschmann for providing support with the McArtim RTM. We thank Caroline Fayt and Michel van Roozendael for providing the WinDOAS software and Thomas Wagner for helpful discussions.

Edited by: M. Van Roozendael

Reviewed by: two anonymous referees

\section{References}

Augustine, J. A., Hodges, G. B., Dutton, E. G., Michalsky, J. J., and Cornwall, C. R.: An aerosol optical depth climatology for NOAA's national surface radiation budget network (SURFRAD), J. Geophys. Res.-Atmos., 113, D11204, doi:10.1029/2007JD009504, 2008. 
Baidar, S., Oetjen, H., Coburn, S., Dix, B., Ortega, I., Sinreich, R., and Volkamer, R.: The CU Airborne MAX-DOAS instrument: vertical profiling of aerosol extinction and trace gases, Atmos. Meas. Tech., 6, 719-739, doi:10.5194/amt-6-719-2013, 2013.

Baidar, S., Kille, N., Ortega, I., Sinreich, R., Thomson, D., Hannigan, J., and Volkamer, R.: Development of a digital mobile solar tracker, Atmos. Meas. Tech., 9, 963-972, doi:10.5194/amt-9963-2016, 2016.

Berg, L. K., Fast, J. D., Barnard, J. C., Burton, S. P., Cairns, B., Chand, D., Comstock, J. M., Dunagan, S., Ferrare, R. A., Flynn, C. J., Hair, J. W., Hostetler, C. A., Hubbe, Jefferson, A., J., Johnson, R., Kassianov, E. I., Kluzek, C. D., Kollias, P., Lamer, K., Lantz, K., Mei, F., Miller, M. A., Michalsky, J., Ortega, I., Pekour, M., Rogers, R. R., Russell, P. B., Redemann III, J., A. J. S., Segal-Rosenheimer, M., Schmid, B., Shilling, J. E., Shinozuka, Y., Springston, S. R., Tomlinson, J. M., Tyrrell, M., Wilson, J. M., Volkamer, R., Zelenyuk, A., and Berkowitz, C. M.: The Two-Column Aerosol Project: phase I-Overview and impact of elevated aerosol layers on aerosol optical depth, J. Geophys. Res.-Atmos., 121, 336-361, doi:10.1002/2015JD023848, 2016.

Bodhaine, B. A., Wood, N. B., Dutton, E. G., and Slusser, J. R.: On Rayleigh Optical Depth Calculations, J. Atmos. Ocean. Tech., 16, 1854-1861, 1999.

Bogumil, K., Orphal, J., Homann, T., Voigt, S., Spietz, P., Fleischmann, O., Vogel, A., Hartmann, M., Kromminga, H., Bovensmann, H., Frerick, J., and Burrows, J.: Measurements of molecular absorption spectra with the SCIAMACHY pre-flight model: instrument characterization and reference data for atmospheric remote-sensing in the $2302380 \mathrm{~nm}$ region, J. Photoch. Photobio. A, 157, 167-184, doi:10.1016/S1010-6030(03)00062-5, 2003.

Bohren, C. F. and Huffman, D. R.: Absorption and Scattering of Light by Small Particles, Wiley, 1998.

Box, M. A. and Deepak, A.: Retrieval of aerosol size distributions by inversion of simulated aureole data in the presence of multiple scattering, Appl. Opt., 18, 1376-1382, 1979.

Chance, K. and Kurucz, R. L.: An improved high-resolution solar reference spectrum for Earth's atmosphere measurements in the ultraviolet, visible, and near infrared, J. Quant. Spectrosc. Ra., 111, 1289-1295, 2010.

Chance, K. V. and Spurr, R. J. D.: Ring effect studies: Rayleigh scattering, including molecular parameters for rotational Raman scattering, and the Fraunhofer spectrum, Appl. Opt., 36, 52245230, doi:10.1364/AO.36.005224, 1997.

Chung, C. E., Ramanathan, V., Kim, D., and Podgorny, I. A.: Global anthropogenic aerosol direct forcing derived from satellite and ground-based observations, J. Geophys. Res.-Atmos., 110, D24207, doi:10.1029/2005JD006356, 2005.

Clémer, K., Van Roozendael, M., Fayt, C., Hendrick, F., Hermans, C., Pinardi, G., Spurr, R., Wang, P., and De Mazière, M.: Multiple wavelength retrieval of tropospheric aerosol optical properties from MAXDOAS measurements in Beijing, Atmos. Meas. Tech., 3, 863-878, doi:10.5194/amt-3-863-2010, 2010.

Deutschmann, T., Beirle, S., Frieß, U., Grzegorski, M., Kern, C., Kritten, L., Platt, U., Prados-Roman, C., Puckimacrte, J.,Wagner, T.,Werner, B., and Pfeilsticker, K.: The Monte Carlo atmospheric radiative transfer model McArtim: Introduction and validation of Jacobians and 3D features, J. Quant. Spectrosc. Ra., 112, 11191137, doi:10.1016/j.jqsrt.2010.12.009, 2011.
Dubovik, O., Smirnov, A., Holben, B. N., King, M. D., Kaufman, Y. J., Eck, T. F., and Slutsker, I.: Accuracy assessments of aerosol optical properties retrieved from Aerosol Robotic Network (AERONET) Sun and sky radiance measurements, J. Geophys. Res.-Atmos., 105, 9791-9806, doi:10.1029/2000JD900040, 2000.

de Beek, R., Vountas, M., Rozanov, V. V., Richter, A., and Burrows, J. P.: The Ring effect in the cloudy atmosphere, Geophys. Res. Lett., 28, 721-724, 2001.

Eck, T. F., Holben, B. N., Reid, J. S., Dubovik, O., Smirnov, A., O'Neill, N. T., Slutsker, I., and Kinne, S.: Wavelength dependence of the optical depth of biomass burning, urban, and desert dust aerosols, J. Geophys. Res.-Atmos., 104, 31333 31349, doi:10.1029/1999JD900923, 1999.

Fast, J. D., Berg, L. K., Zhang, K., Easter, R. C., Ferrare, R. A., Hair, J. W., Hostetler, C. A., Liu, Y., Ortega, I., Sedlacek III, A., Shilling, J. E., Shrivastava, M., Springston, S. R., Tomlinson, J. M., Volkamer, R., Wilson, J., Zaveri R. A., and Zelenyuk, A.: Model Representations of Aerosol Layers Transported from North America over the Atlantic Ocean during the Two-Column Aerosol Project (TCAP), J. Geophys. Res.-Atmos., doi:10.1002/2016JD025248, online first, 2016.

Fayt, C. and Van Roozendael, M.: WinDOAS 2.1, Software User Manual, Belgian Institute for Space Aeronomy, Brussels, Belgium, available at: http://uv-vis.aeronomie.be/software/ WinDOAS/WinDOAS-SUM-210b.pdf (last access: 29 May 2012), 2001.

Frieß, U., Monks, P. S., Remedios, J. J., Rozanov, A., Sinreich, R., Wagner, T., and Platt, U.: MAX-DOAS $\mathrm{O}_{4}$ measurements: A new technique to derive information on atmospheric aerosols: 2. Modeling studies, J. Geophys. Res.-Atmos., 111, D14203, doi:10.1029/2005JD006618, 2006.

Gielen, C., Van Roozendael, M., Hendrick, F., Pinardi, G., Vlemmix, T., De Bock, V., De Backer, H., Fayt, C., Hermans, C., Gillotay, D., and Wang, P.: A simple and versatile cloudscreening method for MAX-DOAS retrievals, Atmos. Meas. Tech., 7, 3509-3527, doi:10.5194/amt-7-3509-2014, 2014.

Gisi, M., Hase, F., Dohe, S., and Blumenstock, T.: Camtracker: a new camera controlled high precision solar tracker system for FTIR-spectrometers, Atmos. Meas. Tech., 4, 47-54, doi:10.5194/amt-4-47-2011, 2011.

Grainger, J. and Ring, J.: Anomalous Fraunhofer Line Profiles, Nature, 193, 762, doi:10.1038/193762a0, 1962.

Hair, J. W., Hostetler, C. A., Cook, A. L., Harper, D. B., Ferrare, R. A., Mack, T. L., Welch, W., Izquierdo, L. R., and Hovis, F. E.: Airborne High Spectral Resolution Lidar for profiling aerosol optical properties, Appl. Opt., 47, 6734-6752, 2008.

Hansen, J., Sato, M., Nazarenko, L., Ruedy, R., Lacis, A., Koch, D., Tegen, I., Hall, T., Shindell, D., Santer, B., Stone, P., Novakov, T., Thomason, L., Wang, R., Wang, Y., Jacob, D., Hollandsworth, S., Bishop, L., Logan, J., Thompson, A., Stolarski, R., Lean, J., Willson, R., Levitus, S., Antonov, J., Rayner, N., Parker, D., and Christy, J.: Climate forcings in Goddard Institute for Space Studies SI2000 simulations, J. Geophys. Res.-Atmos., 107, 4347, doi:10.1029/2001JD001143, 2002.

Harrison, L., Michalsky, J., and Berndt, J.: Automated multi-filter rotation shadow-band radiation measurements, Appl. Opt., 33, 5118-5125, doi:10.1364/AO.33.005118, 1994. 
Herman, J., Cede, A., Spinei, E., Mount, G., Tzortziou, M., and Abuhassan, N.: $\mathrm{NO}_{2}$ column amounts from ground-based Pandora and MFDOAS spectrometers using the direct sun DOAS technique: Intercomparisons and application to OMI validation, J. Geophys. Res., 114, D13307, doi:10.1029/2009JD011848, 2009.

Henyey, L. G. and Greenstein, J. L.: Diffuse radiation in the galaxy, Astrophys. J., 93, 70-83, doi:10.1086/144246, 1941.

Holben, B., Eck, T., Slutsker, I., Tanré, D., Buis, J., Setzer, A., Vermote, E., Reagan, J., Kaufman, Y., Nakajima, T., Lavenu, F., Jankowiak, I., and Smirnov, A.: AERONET - A Federated Instrument Network and Data Archive for Aerosol Characterization, Remote Sens. Environ., 66, 1-16, doi:10.1016/S00344257(98)00031-5, 1998.

Holben, B. N., Tanré, D., Smirnov, A., Eck, T. F., Slutsker, I., Abuhassan, N., Newcomb, W. W., Schafer, J. S., Chatenet, B., Lavenu, F., Kaufman, Y. J., Castle, J. V., Setzer, A., Markham, B., Clark, D., Frouin, R., Halthore, R., Karneli, A., O’Neill, N. T., Pietras, C., Pinker, R. T., Voss, K., and Zibordi, G.: An emerging ground-based aerosol climatology: Aerosol optical depth fromAERONET, J. Geophys. Res.-Atmos., 106, 12067-12097, doi:10.1029/2001JD900014, 2001.

Hönninger, G., von Friedeburg, C., and Platt, U.: Multi axis differential optical absorption spectroscopy (MAX-DOAS), Atmos. Chem. Phys., 4, 231-254, doi:10.5194/acp-4-231-2004, 2004.

Intergovernmental Panel on Climate Change: Climate Change 2013: The Physical Science Basis, Cambridge University Press, Cambridge, UK and New York, NY, USA, 2013.

Kassianov, E., Berg, L. K,; Pekour, M., Barnard, J., Chand, D., Flynn, C., Ovchinnikov, M., Sedlacek, A., Schmid, B., Shilling, J., Tomlinson, J., and Fast, J.: Airborne aerosol in situ measurements during TCAP: A closure study of total scattering, Atmosphere, 6, 1069-1101, doi:10.3390/atmos6081069, 2015.

Kaufman, Y. J., Gitelson, A., Karnieli, A., Ganor, E., Fraser, R. S., Nakajima, T., Mattoo, S., and Holben, B. N.: Size distribution and scattering phase function of aerosol particles retrieved from sky brightness measurements, J. Geophys. Res., 99, 1034110356, doi:10.1029/94JD00229, 1994.

Kraus, S.: DOASIS - A Framework design for DOAS, PhD Thesis, Mannheim University, 2006.

Langford, A. O., Schofield, R., Daniel, J. S., Portmann, R. W., Melamed, M. L., Miller, H. L., Dutton, E. G., and Solomon, S.: On the variability of the Ring effect in the near ultraviolet: understanding the role of aerosols and multiple scattering, Atmos. Chem. Phys., 7, 575-586, doi:10.5194/acp-7-575-2007, 2007.

Mao, K., Ma, Y., Xia, L., Chen, W. Y., Shen, X., He, T., and $\mathrm{Xu}$, T.: Global aerosol change in the last decade: An analysis based on MODIS data, Atmos. Environ., 94, 680-686, doi:10.1016/j.atmosenv.2014.04.053, 2014.

McComiskey, A., Schwartz, S. E., Schmid, B., Guan, H., Lewis, E. R., Ricchiazzi, P., and Ogren, J. A.: Direct aerosol forcing: Calculation from observables and sensitivities to inputs, J. Geophys. Res.-Atmos., 113, D09202, doi:10.1029/2007JD009170, 2008.

Michalsky, J., Denn, F., Flynn, C., Hodges, G., Kiedron, P., Koontz, A., Schlemmer, J., and Schwartz, S. E.: Climatology of aerosol optical depth in north-central Oklahoma: 1992-2008, J. Geophys. Res.-Atmos., 115, D07203, doi:10.1029/2009JD012197, 2010.
Müller, D., Hostetler, C. A., Ferrare, R. A., Burton, S. P., Chemyakin, E., Kolgotin, A., Hair, J. W., Cook, A. L., Harper, D. B., Rogers, R. R., Hare, R. W., Cleckner, C. S., Obland, M. D., Tomlinson, J., Berg, L. K., and Schmid, B.: Airborne Multiwavelength High Spectral Resolution Lidar (HSRL-2) observations during TCAP 2012: vertical profiles of optical and microphysical properties of a smoke/urban haze plume over the northeastern coast of the US, Atmos. Meas. Tech., 7, 3487-3496, doi:10.5194/amt-7-3487-2014, 2014.

Nakajima, T., Tanaka, M., and Yamauchi, T.: Retrieval of the optical properties of aerosols from aureole and extinction data, Appl. Opt., 22, 2951-2959, 1983.

Nakajima, T., Tonna, G., Rao, R., Boi, P., Kaufman, Y., and Holben, B.: Use of sky brightness measurements from ground for remote sensing of particulate polydispersions, Appl. Opt., 35, 2672-2686, doi:10.1364/AO.35.002672, 1996.

Ortega, I., Koenig, T., Sinreich, R., Thomson, D., and Volkamer, R.: The CU 2-D-MAX-DOAS instrument - Part 1: Retrieval of 3-D distributions of $\mathrm{NO}_{2}$ and azimuth-dependent OVOC ratios, Atmos. Meas. Tech., 8, 2371-2395, doi:10.5194/amt-8-2371-2015, 2015.

Ortega, I., Berg, L., Ferrare, R., Johnathan, H., Hostetler, C., and Volkamer, R.: Elevated aerosol layers modify the $\mathrm{O}_{2}-\mathrm{O}_{2}$ absorption measured by ground based MAX-DOAS, J. Quant. Spectrosc. Ra., 176, 34-49, doi:10.1016/j.jqsrt.2016.02.021, 2016.

Platt, U. and Stutz, J.: Differential Optical Absorption Spectroscopy, Springer, Berlin, 597 pp., doi:10.1007/978-3-54075776-4, 2008.

Remer, L. A., Kleidman, R. G., Levy, R. C., Kaufman, Y. J., Tanré, D., Mattoo, S., Martins, J. V., Ichoku, C., Koren, I., Yu, H., and Holben, B. N.: Global aerosol climatology from the MODIS satellite sensors, J. Geophys. Res.-Atmos., 113, D14S07, doi:10.1029/2007JD009661, 2008.

Sinreich, R., Coburn, S., Dix, B., and Volkamer, R.: Ship-based detection of glyoxal over the remote tropical Pacific Ocean, Atmos. Chem. Phys., 10, 11359-11371, doi:10.5194/acp-1011359-2010, 2010.

Sinyuk, A., Holben, B. N., Smirnov, A., Eck, T. F., Slutsker, I., Schafer, J. S., Giles, D. M., and Sorokin, M.: Assessment of error in aerosol optical depth measured by AERONET due to aerosol forward scattering, Geophys. Res. Lett., 39, L23806, doi:10.1029/2012GL053894, 2012.

Torres, B., Toledano, C., Berjón, A., Fuertes, D., Molina, V., Gonzalez, R., Canini, M., Cachorro, V. E., Goloub, P., Podvin, T., Blarel, L., Dubovik, O., Bennouna, Y., and de Frutos, A. M.: Measurements on pointing error and field of view of Cimel318 Sun photometers in the scope of AERONET, Atmos. Meas. Tech., 6, 2207-2220, doi:10.5194/amt-6-2207-2013, 2013.

Vandaele, A. C., Hermans, C., Simon, P. C., Carleer, M., Colin, R., Fally, S., Mérienne, M. F., Jenouvrier, A., and Coquart, B.: Measurements of the $\mathrm{NO}_{2}$ absorption cross section from $42000 \mathrm{~cm}^{-1}$ to $10000 \mathrm{~cm}^{-1}(238-1000 \mathrm{~nm})$ at $220 \mathrm{~K}$ and $294 \mathrm{~K}$, J. Quant. Spectrosc. Ra., 59, 171-184, doi:10.1016/S0022-4073(97)00168-4, 1998.

Vogel, L., Sihler, H., Lampel, J., Wagner, T., and Platt, U.: Retrieval interval mapping: a tool to visualize the impact of the spectral retrieval range on differential optical absorption spectroscopy evaluations, Atmos. Meas. Tech., 6, 275-299, doi:10.5194/amt-6275-2013, 2013. 
Volkamer, R., Baidar, S., Campos, T. L., Coburn, S., DiGangi, J. P., Dix, B., Eloranta, E. W., Koenig, T. K., Morley, B., Ortega, I., Pierce, B. R., Reeves, M., Sinreich, R., Wang, S., Zondlo, M. A., and Romashkin, P. A.: Aircraft measurements of BrO, IO, glyoxal, $\mathrm{NO}_{2}, \mathrm{H}_{2} \mathrm{O}, \mathrm{O}_{2}-\mathrm{O}_{2}$ and aerosol extinction profiles in the tropics: comparison with aircraft-/ship-based in situ and lidar measurements, Atmos. Meas. Tech., 8, 2121-2148, doi:10.5194/amt-8-2121-2015, 2015.

Vountas, M., Rozanov, V. V., and Burrows, J. P.: Ring effect: Impact of rotational Raman scattering on radiative transfer in earth's atmosphere, J. Quant. Spectrosc. Ra., 60, 943-961, 1998.

Vountas, M., Richter, A., Wittrock, F., and Burrows, J. P.: Inelastic scattering in ocean water and its impact on trace gas retrievals from satellite data, Atmos. Chem. Phys., 3, 1365-1375, doi:10.5194/acp-3-1365-2003, 2003.

Wagner, T., Dix, B., Friedeburg, C. v., Frieß, U., Sanghavi, S., Sinreich, R., and Platt, U.: MAX-DOAS $\mathrm{O}_{4}$ measurements: A new technique to derive information on atmospheric aerosolsPrinciples and information content, J. Geophys. Res.-Atmos., 109, D22205, doi:10.1029/2004JD004904, 2004.

Wagner, T., Burrows, J. P., Deutschmann, T., Dix, B., von Friedeburg, C., Frieß, U., Hendrick, F., Heue, K.-P., Irie, H., Iwabuchi, H., Kanaya, Y., Keller, J., McLinden, C. A., Oetjen, H., Palazzi, E., Petritoli, A., Platt, U., Postylyakov, O., Pukite, J., Richter, A., van Roozendael, M., Rozanov, A., Rozanov, V., Sinreich, R., Sanghavi, S., and Wittrock, F.: Comparison of box-airmass-factors and radiances for Multiple-Axis Differential Optical Absorption Spectroscopy (MAX-DOAS) geometries calculated from different UV/visible radiative transfer models, Atmos. Chem. Phys., 7, 1809-1833, doi:10.5194/acp-7-1809-2007, 2007.
Wagner, T., Beirle, S., and Deutschmann, T.: Three-dimensional simulation of the Ring effect in observations of scattered sun light using Monte Carlo radiative transfer models, Atmos. Meas. Tech., 2, 113-124, doi:10.5194/amt-2-113-2009, 2009a.

Wagner, T., Deutschmann, T., and Platt, U.: Determination of aerosol properties from MAX-DOAS observations of the Ring effect, Atmos. Meas. Tech., 2, 495-512, doi:10.5194/amt-2-4952009, 2009b.

Wagner, T., Beirle, S., Deutschmann, T., and Penning de Vries, M.: A sensitivity analysis of Ring effect to aerosol properties and comparison to satellite observations, Atmos. Meas. Tech., 3, 1723-1751, doi:10.5194/amt-3-1723-2010, 2010.

Wagner, T., Apituley, A., Beirle, S., Dörner, S., Friess, U., Remmers, J., and Shaiganfar, R.: Cloud detection and classification based on MAX-DOAS observations, Atmos. Meas. Tech., 7, 1289-1320, doi:10.5194/amt-7-1289-2014, 2014.

Wang, Y., Li, A., Xie, P. H., Wagner, T., Chen, H., Liu, W. Q., and Liu, J. G.: A rapid method to derive horizontal distributions of trace gases and aerosols near the surface using multi-axis differential optical absorption spectroscopy, Atmos. Meas. Tech., 7, 1663-1680, doi:10.5194/amt-7-1663-2014, 2014.

Westervelt, D. M., Horowitz, L. W., Naik, V., Golaz, J.-C., and Mauzerall, D. L.: Radiative forcing and climate response to projected 21st century aerosol decreases, Atmos. Chem. Phys., 15, 12681-12703, doi:10.5194/acp-15-12681-2015, 2015. 